NBER WORKING PAPER SERIES

DEPOSIT INSURANCE AND ORDERLY LIQUIDATION WITHOUT COMMITMENT:

CAN WE SLEEP WELL?

\author{
Russell Cooper \\ Hubert Kempf \\ Working Paper 19132 \\ http://www.nber.org/papers/w19132
NATIONAL BUREAU OF ECONOMIC RESEARCH
1050 Massachusetts Avenue
Cambridge, MA 02138
June 2013

Russell Cooper is grateful to the NSF for financial support. Comments from Todd Keister, Antoine Martin, Jonathan Willis and seminar participants at the Banque de France, the University of Bologna, the Central Bank of Turkey, Koc University, the RMM Conference 2010 at the University of Toronto, Washington University at St. Louis, the Riksbank, the University of Pennsylvania, Rice University, the University of Iowa, the Tinbergen Institute and the Federal Reserve Bank of Kansas City are appreciated. The views expressed herein are those of the authors and do not necessarily reflect the views of the National Bureau of Economic Research.

NBER working papers are circulated for discussion and comment purposes. They have not been peerreviewed or been subject to the review by the NBER Board of Directors that accompanies official NBER publications.

(C) 2013 by Russell Cooper and Hubert Kempf. All rights reserved. Short sections of text, not to exceed two paragraphs, may be quoted without explicit permission provided that full credit, including $\odot$ notice, is given to the source. 
Deposit Insurance and Orderly Liquidation without Commitment: Can we Sleep Well?

Russell Cooper and Hubert Kempf

NBER Working Paper No. 19132

June 2013

JEL No. E42,E58,G01,G18

\begin{abstract}
$\underline{\text { ABSTRACT }}$
This paper assess the affects of the orderly liquidation of a failing bank and the ex post provision of deposit insurance on the prospect of bank runs. Assuming that the public institutions in charge of these policies lack commitment power, these interventions, both individually and jointly, are chosen and undertaken ex post. The costs of liquidation and redistribution across heterogenous households play key roles in these decisions. If investment is suffciently illiquid, a credible liquidation policy will deter runs. Deposit insurance will not be provided ex post if it requires a (socially) undesirable redistribution of consumption that outweighs insurance gains. Despite the lack of commitment, runs can be prevented by the provision of deposit insurance funded by an optimally designed ex post tax scheme.
\end{abstract}

\author{
Russell Cooper \\ Department of Economics \\ The Pennsylvania State University \\ 611 Kern \\ State College, PA 16802 \\ and NBER \\ russellcoop@gmail.com \\ Hubert Kempf \\ Ecole Normale Superieure, Cachan \\ and Paris School of Economics \\ kempf@univ-paris1.fr
}




\title{
Deposit Insurance and Bank Liquidation without Commitment: Can we Sleep Well?*
}

\author{
Russell Cooper ${ }^{\dagger}$ and Hubert Kempf ${ }^{\dagger}$
}

June 28, 2014

\begin{abstract}
This paper assess the affects of the orderly liquidation of a failing bank and the ex post provision of deposit insurance on the prospect of bank runs. Assuming that the public institutions in charge of these policies lack commitment power, these interventions, both individually and jointly, are chosen and undertaken ex post. The costs of liquidation and redistribution across heterogenous households play key roles in these decisions. If investment is sufficiently illiquid, a credible liquidation policy will deter runs. Deposit insurance will not be provided ex post if it requires a (socially) undesirable redistribution of consumption that outweighs insurance gains. Despite the lack of commitment, runs can be prevented by the provision of deposit insurance funded by an optimally designed ex post tax scheme.
\end{abstract}

\section{Introduction}

Sleep well, knowing that since the creation of the FDIC in 1934, no depositor has ever lost one penny of insured deposits. ${ }^{1}$

This quote captures the widely held belief that a government institution, such as the FDIC, will support the depositors of failed banks through deposit insurance. Within the framework of Diamond and Dybvig (1983), the implications of deposit insurance are well understood. If agents believe that deposit insurance will be provided, then bank runs, driven by beliefs, will not occur. In equilibrium, the government need

\footnotetext{
${ }^{*}$ Russell Cooper is grateful to the NSF for financial support. Comments from Todd Keister, Antoine Martin, Jonathan Willis and seminar participants at the Banque de France, the University of Bologna, the Central Bank of Turkey, Koc University, the RMM Conference 2010 at the University of Toronto, Washington University at St. Louis, the Riksbank, the University of Pennsylvania, Rice University, the University of Iowa, the Tinbergen Institute and the Federal Reserve Bank of Kansas City are appreciated.

${ }^{\dagger}$ Economics Department, Pennsylvania State University, russellcoop@gmail.com

${ }^{\ddagger}$ Ecole Normale Superieure de Cachan and Paris School of Economics, hubert.kempf@ens-cachan.fr.

${ }^{1}$ From http://www.fdic.gov/deposit/deposits/penny/.
} 
not act: deposit insurance is never provided and costly liquidations are avoided. Instead, deposit insurance works through its effects on beliefs, supported by the commitment of a government to its provision.

Yet, recent events during the financial crisis lead one to question this commitment of the government. In many countries, such as the US, the parameters of deposit insurance were adjusted during the crisis period. Even increased provision of deposit insurance is evidence that the terms of the program is not completely established ex ante In other countries, such as UK, ambiguities about the deposit insurance program contributed to banking instability. In yet other countries, such as China, the exact nature of deposit insurance is not explicit. And, in Europe, the combination of a common currency, the commitment of the ECB not to bailout member governments and fiscal restrictions, cast some doubt upon the ability of individual countries to finance deposit insurance as needed. If the country specific deposit funds are unable to meet the demands under a systemic run, then how will deposit insurance be provided?

The late March 2013 Cypriot banking crisis is a telling example of commitment problems and the ensuing political and economic difficulties a country faces in funding deposit insurance and the management of failing banks. Decisions were made ex post in a politicized setting which highlighted the redistributive dimensions of the provision of deposit insurance, both across groups of claimants and national borders. Negotiations between the IMF, the EU and the newly elected Cypriot government, as well as the public debate once the first proposal was made public, were about the use of taxation to provide deposit insurance, the level of caps on deposits and the orderly liquidation of part of the banking system. The final agreement favored a fraction of depositors, which were protected, at the expenses of rich ones who were de facto taxed. ${ }^{2}$

Going beyond this select group of countries, Demirgüç-Kunt and Sobaci (2001) provides a detailed account of deposit insurance across a wide range of countries around 2000. Evidently, both explicit and implicit deposit insurance schemes exist. For the explicit ones, some but not all are fully supported by public funding. There are mixtures of private and public schemes. In the absence of explicit publicly funded deposit insurance plans, there is surely the potential for commitment problems to arise.

Finally, there is also the question of how broadly to define a bank and thus the types of financial arrangements deposit insurance (in some cases interpretable as an ex post bailout) might cover. ${ }^{3}$ The bailout of AIG, for example, along with the choice not to bail out Lehman Brothers, makes clear that some form of deposit insurance is possible ex post for some, but not all, financial intermediaries.

The above quote from the FDIC does not pertain to these near-banks as they are not covered by deposit insurance. Recent US legislation, the so-called Dodd-Frank bill, provides a process, termed an "Orderly Liquidation Authority", hereafter OLA, to deal with failed financial institutions outside of the FDIC system. In fact, this regulation was partly motivated by the need to make explicit the government's role in the event

\footnotetext{
${ }^{2}$ Another interesting case is the Dutch system which is apparently, see http://www.dnb.nl/en/about-dnb/ consumers-and-dnb/consumers-and-supervision/depositogarantiestelsel/index.jsp, a private deposit insurance scheme with an implicit government backstop.

${ }^{3}$ This was brought out clearly in a presentation, http://www.federalreserve.gov/newsevents/speech/bernanke20100924a. htm, by Ben Bernanke at Princeton University in September 2010.
} 
of financial failures. As U.S. President Obama put it "Never again will American Taxpayers be held hosting by a bank that is too big to fail." ${ }^{4}$ In these instances, the regulators control the disposition of bank assets.

Taken together, these events highlight ambiguities about the nature of interventions in the banking system, including the provision and extent of deposit insurance and its coordination with liquidation decisions. This motivates our study of interventions, through OLA and DI, without any commitment. In the case of OLA, a regulator intervenes as soon as a run is underway, takes control of the bank, decides on the liquidation of long-term assets and recontracts with non-served depositors. In the case of DI, the bank fully liquidates its long-term assets and serves a fraction of early withdrawers. A Treasury provides funds to the non-served withdrawers to fulfill the deposit contract, and finances this outflow by taxes.

Admittedly the no-commitment assumption is extreme. It highlights what measures will be undertaken without ex ante commitment by public authorities. A finding that deposit insurance will be provided $e x$ post without any commitment whatsoever establishes a firmer basis for the benefits of this insurance. A finding that deposit insurance will not be provided ex post suggests guidelines for policy design ex ante to change these ex post incentives and to strengthen any existing commitments of the government. Likewise, characterizing the optimal liquidation policy ex post is relevant when authorities have discretion over the assets of a failed banking institution.

As we shall discover, the ex post incentives for deposit insurance interact with the liquidation policy. Further, the prevention of runs depends on these policies. Credible provision of deposit insurance along with the credible protection of illiquid investments is sufficient to prevent runs. In some cases, a credible liquidation policy alone can prevent runs.

There are two central building blocks for our analysis: (i) a model of banking along the lines of Diamond and Dybvig (1983) and (ii) the lack of commitment leading governments to make ex post decisions about the liquidation and deposit insurance. In this setting, a trade-off emerges between the gains from transfers to depositors who were not served in a bank run and the potential costs of redistribution and liquidation to fund these transfers.

The standard argument about gains to deposit insurance, as in Diamond and Dybvig (1983), is present in the ex post choice of providing deposit insurance since agents face the risk of obtaining a zero return on deposits in the event of a run. But there are potential costs of redistribution across heterogeneous households. This depends on the social objective function. If the social objective favors equality of consumption, then the provision of deposit insurance may lead to less equal consumption distributions and thus be socially costly. ${ }^{5}$

Whether this trade-off leads to the provision to deposit insurance ex post depends, in part, on the tax system used to fund this insurance. If the taxes needed to fund deposit insurance are determined ex post along with the decision on deposit insurance itself, we find that deposit insurance will always be provided. Put differently, if there is no commitment to deposit insurance, then it is preferable to have ex post flexibility

\footnotetext{
${ }^{4}$ From http://www. whitehouse.gov/blog/2010/01/21/president-obama-never-again-will-american-taxpayer-be-held-hostage-a-bank-tc

${ }^{5}$ These costs of redistribution play a key role in the Cooper, Kempf, and Peled (2008) study of bailout of one region by others in a fiscal federation.
} 
to design a tax system to fund it. In this case, the trade-off between insurance and redistribution disappears and liquidation decisions are optimal.

In our analysis, the capacity for redistribution is progressively limited so that a trade-off emerges between redistribution and insurance. Richer households will gain from deposit insurance simply because of their larger claims on the banking system. Unless these claims are offset by progressive taxes to fund deposit insurance, the provision of deposit insurance is regressive: transferring resources from the poor to the rich. If this redistribution runs counter to social welfare, then deposit insurance may not be provided ex post despite insurance gains. However, partial deposit insurance, in the form of a cap on the amount insured, will generally be provided ex post.

As in Ennis and Keister (2009), the government is also unable to commit to a liquidation policy. Instead, it is determined ex post. Inefficient liquidations may be used instead of deposit insurance, for both insurance and redistributive gains. The crucial parameter is the cost of liquidation. If illiquid investments are not easily convertible into current consumption goods, then ex post, the regulator will choose to protect the assets of the bank and thus prevent runs. Else, liquidation will occur ex post and runs may not be prevented.

When taxes to fund deposit insurance are optimally set ex post, inefficient liquidations do not occur and runs are prevented. In this case, the tax system is sufficiently flexible to provide insurance without costly redistribution. Inefficiently liquidations are not needed and, in fact, a policy which suspends withdrawals to stop a run is credible.

These results build upon the bank runs literature starting with the contribution of Diamond and Dybvig (1983). With few exceptions, policy in this environment are studied under the assumption of full commitment. Ennis and Keister (2009) focus on ex post interventions in the form of a "deposit freeze" and payment rescheduling. An important feature of that analysis is the lack of commitment: the decision on the policy intervention arises during the run. Keister (2010) studies the trade-off between the ex ante incentive effects and ex post gains to a bailout. Here the attention is on the design of ex ante measures given the prospect of a bailout ex post.

Neither of those papers focus on the heterogeneity across households and thus the redistributive aspects of deposit insurance and liquidation. The redistributive effects of different forms of bailouts are surely present in the ongoing political debate. These effects are central to the contribution of this paper. ${ }^{6}$

Further, our analysis looks jointly at liquidation policy and deposit insurance in an environment without commitment to either form of intervention. As our analysis demonstates, these policies interact. The effect of deposit insurance on runs depends, in part, on whether illiquid assets are liquidated. Further, the liquidation decision depends on the form of deposit insurance as well as the taxation used to finance it. If the tax system to finance deposit insurance is set optimally ex post, then deposit insurance will be provided ex post. In this case, runs are prevented without costly liquidation.

\footnotetext{
${ }^{6}$ This paper subsumes Cooper and Kempf (2011) which focused more narrowly on deposit insurance assuming a liquidation policy.
} 


\section{Decentralized Allocation}

We study a decentralized allocation through bank contracts. This approach has a couple of advantages. First, it allows us to distinguish the three important actors in the problem: households, banks and the government. Second, we can focus on government provision of deposit insurance and the taxation to finance this redistribution. This provides some insights into the trade-off between redistribution and insurance.

We first present the contracting environment, detailing feasible contracts and the role of sequential service. We then turn to the optimization problems of households and banks.

\section{$2.1 \quad$ Environment}

The model is a version of Diamond and Dybvig (1983) with heterogeneity across the endowments and hence deposits of agents. The model is structured to highlight a tension across agents based upon their claims on the financial system.

There are three periods, with $t=0,1,2$. In periods 0 and 1 , each household receives an endowment of the single good denoted $\alpha=\left(\alpha^{0}, \bar{\alpha}\right)$. We index households by their period 0 endowment and refer to them as "endowment type" $\alpha^{0}$, or simply agent type when there is no ambiguity. Let $f\left(\alpha^{0}\right)$ be the pdf and $F\left(\alpha^{0}\right)$ the cdf of the period 0 endowment distribution with $F\left(\alpha_{-}\right) \geq 0$ and $F\left(\alpha_{+}\right)=1$ at the lower $\left(\alpha_{-}\right)$and upper $\left(\alpha_{+}\right)$supports of the distribution. This heterogeneity reflects both innate differences across agents as well as the outcome of ex ante redistributive government policies. ${ }^{7}$

Households consume in either period 1, or in period 2. In the former case, households are called "early" consumers, in the latter case, "late" consumers. Hereafter we term this the "taste type" of the household. The fraction of early consumers for each household endowment type is $\pi$. The preferences of households are determined at the start of period 1 . Utility in periods 1 and 2 is given by $v\left(c^{E}\right)$ if the household is an early consumer and by $v\left(c^{L}\right)$ if the household is a late consumer. Assume $v(\cdot)$ is strictly increasing and strictly concave. Some results require that $\zeta v^{\prime}(\zeta c+\bar{\alpha})$ is increasing in $\zeta$. This is a restriction on the curvature of $v(\cdot)$ and is similar to assuming that substitution effects dominate income effects in a static labor supply problem.

There are three important assumptions about the environment. First, $\pi$ is independent of $\alpha^{0}$. Second, there is no aggregate uncertainty in $\pi$. Third, while the endowment type of a household is observed by the bank, her taste type is private information. This is important for the discussion of bank runs.

There are two storage technologies available in the economy. There is a one period technology which generates a unit of the good in period $t+1$ from each unit stored in period $t$. Late households can store their period 1 endowment using this technology.

There is also a two period technology which yields a return of $R>1$ in period 2 for each unit stored in period 0. This technology is illiquid though: it has a return of $\epsilon \leq 1$ if it is interrupted in period 1 . If $\epsilon<1$, there is a non-trivial choice between investing in the two technologies.

\footnotetext{
${ }^{7}$ We do not study this ex ante problem explicitly but rather focus on ex post redistribution following a bank run.
} 
The economy is assumed to be competitive. Households and banks act as price takers. Neither households nor banks are large enough to impact the choices of the government. ${ }^{8}$

\subsection{Contracts and Sequential Service}

Banks offer contracts to depositors. A contract is dependent on the household endowment type as $\alpha^{0}$ is observable. The taste type of the household is not observable to the bank. A contract stipulates a return on deposits in the two periods, $\left(r^{E}\left(\alpha^{0}\right), r^{L}\left(\alpha^{0}\right)\right)$, for type $\alpha^{0}$.

The contract is implemented through sequential service. The contract we study and our model of sequential service are close to Diamond and Dybvig (1983).

It stipulates one and two period returns per unit deposited for each endowment type. We call this a simple contract in the discussion that follows. Our focus on these contracts comes from a version of sequential service in which agents are unaware of their place in the queue. Thus it is not possible to makes consumption allocations dependent on their place in line, as in Green and Lin (2000), or dependent on how many depositors have been served before them, as in Peck and Shell (2003).

Relative to the camping trip analogy of Wallace (1988), it is as if the campers had access to a cash machine (through an iPad or smartphone) that allowed them to simultaneously request a withdrawal. Yet, behind the scenes, the system that delivers the actual funds to the multiple banking machines works in a sequential manner. In this way, it is not feasible to condition the withdrawal of one depositor on the actions of others. Relative to the model of Peck and Shell (2003), we assume that depositors are unable to observe the number of other depositors in line and the bank tellers are unable to keep track of the number of customers served.

We impose these strong informational restrictions on the process of sequential service to provide a basis for the simple contract. We do so for a couple of reasons. First, our focus is on the provision of deposit insurance given a run, rather than the conditions for runs. If we find, as we do, that deposit insurance is optimally provided ex post, then we see that the simple contract does indeed uniquely implement the full-information allocation. Second, deposit contracts do indeed take this simple form. If deposit insurance is provided, then we are rationalizing the choice of this contract.

As in Diamond and Dybvig (1983), we assume that neither the bank nor its customers place positive probability on a bank run. We study the possibility of runs given an optimal simple contract.

Overall, our problem is structured to address a particular question: assuming banks offer the simple contracts associated with the full-information allocation, will the government have an incentive to intervene through orderly liquidation and/or deposit insurance? If the government chooses to do so, then the choice of the simple contract, ignoring the possibility of runs, is rationalized. If the government does not intervene and prevent runs, then of course the contracting problem has to be restructured to take this into account. We do not tackle that problem here.

\footnotetext{
${ }^{8}$ As in Chari and Kehoe (1990), the government is the only large player in the game.
} 


\subsection{Bank Optimization}

Competitive banks offer contracts to households. Through this competition, the equilibrium outcome will maximize household utility subject to a zero expected profit constraint. Since household types are observable, the contracts will be dependent on $\alpha^{0}{ }^{9}$

The bank chooses a contract and an investment plan, $\left(r^{E}\left(\alpha^{0}\right), r^{L}\left(\alpha^{0}\right), \phi\left(\alpha^{0}\right)\right)$ to maximize household utility, subject to a zero expected profit constraint for each type $\alpha^{0} .{ }^{10}$ The bank places a fraction of deposits, $\phi\left(\alpha^{0}\right)$, into the liquid storage technology which yields a unit in either period 1 per unit deposited in period 0 or in period 2 per unit deposited in period 1 . The remainder is deposited into the illiquid technology.

The zero expected profit condition for a type $\alpha^{0}$ contract is:

$$
r^{E}\left(\alpha^{0}\right) \pi \alpha^{0}+r^{L}\left(\alpha^{0}\right)(1-\pi) \alpha^{0}=\phi\left(\alpha^{0}\right) \alpha^{0}+\left(1-\phi\left(\alpha^{0}\right)\right) \alpha^{0} R .
$$

To guarantee the bank can meet the needs of customers, the following constraints on its portfolio must hold as well:

$$
\phi\left(\alpha^{0}\right) \alpha^{0} \geq r^{E}\left(\alpha^{0}\right) \alpha^{0} \pi \quad \text { and } \quad\left(1-\phi\left(\alpha^{0}\right)\right) \alpha^{0} R \geq r^{L}\left(\alpha^{0}\right)(1-\pi) \alpha^{0} .
$$

Clearly if the two constraints in (2) hold with equality, then the zero expected profit condition is met. Note that these conditions hold for any level of deposits.

The expected utility of a household given a contract is given by $U_{\alpha^{0}}(\cdot)=\pi v\left(\bar{\alpha}+\chi^{E}\left(\alpha^{0}\right)\right)+(1-\pi) v(\bar{\alpha}+$ $\left.\chi^{L}\left(\alpha^{0}\right)\right)$. Here $\chi^{i}\left(\alpha^{0}\right) \equiv r^{i}\left(\alpha^{0}\right) \alpha^{0}$ is the total return to a deposit with endowment $\alpha^{0}$ in period $i=E, L$. It is more direct and without loss of generality to characterize the contract in terms of the total return $\chi^{i}(\cdot)$ instead of the return per unit of endowment.

\subsection{Full-Information Allocation}

The decentralized allocation maximizes $U_{\alpha^{0}}\left(\chi^{E}\left(\alpha^{0}\right), \chi^{L}\left(\alpha^{0}\right)\right)$ subject to (1) and (2) for each $\alpha^{0}$. The firstorder condition implies

$$
v^{\prime}\left(\bar{\alpha}+\chi^{E}\left(\alpha^{0}\right)\right)=R v^{\prime}\left(\bar{\alpha}+\chi^{L}\left(\alpha^{0}\right)\right) .
$$

In addition, the constraints in (2) are binding so that (1) holds. Both conditions characterize optimal insurance across the two preference states for a household of type $\alpha^{0}$.

Denote this allocation by $\left(\chi^{* E}\left(\alpha^{0}\right), \chi^{* L}\left(\alpha^{0}\right)\right)$. It will serve as a benchmark in the analysis that follows. In particular, consumptions of both early and late consumers are increasing in the level of endowment, $\alpha^{0}$.

Proposition 1 Both $\chi^{* E}\left(\alpha^{0}\right)$ and $\chi^{* L}\left(\alpha^{0}\right)$ are increasing in $\alpha^{0}$.

\footnotetext{
${ }^{9}$ Later we explore a case with restricted contracts in which private information makes this dependence infeasible.

${ }^{10} \mathrm{As}$ runs are not contemplated, there is no liquidation policy in place at the bank.
} 
Proof. From the first-order condition, (3), $\chi^{* E}\left(\alpha^{0}\right)$ is increasing in $\alpha^{0}$ iff $\chi^{* L}\left(\alpha^{0}\right)$ is increasing in $\alpha^{0}$. So either both consumption levels increase in $\alpha^{0}$ or both decrease. Since the contract for each $\alpha^{0}$ yields the bank zero profit, (1), households with higher $\alpha^{0}$ and hence larger deposits receive higher levels of both early and late consumption compared to households with a lower $\alpha^{0}$. A contract supplying less to both early and late households would be suboptimal.

In this equilibrium, $R>1$ implies that $\bar{\alpha}+\chi^{* E}\left(\alpha^{0}\right)<\bar{\alpha}+\chi^{* L}\left(\alpha^{0}\right)$. That is, the consumption of late consumers exceeds that of early consumers for each type $\alpha^{0}$. Thus there is no incentive compatible for late consumers to pretend to be early consumers, given that all other late consumers are patient and wait until period 2 to withdraw from any of the banks.

In equilibrium, the composition of banks in terms of endowment types is not determined. For convenience, we will focus on a decentralization in which a bank serves only a single endowment type.

\subsection{Systemic Runs}

As is well understood in the literature, there can be another equilibrium associated with a bank run. Since agents' taste types are private information, late households may choose to attempt to withdraw in period 1 if other late households are doing so as well.

We ask two questions. ${ }^{11}$ First, can there be a bank run? Second, if so, will the government have an incentive to intervene, given its available tools?

In this section, we assume there are runs by all agents on all banks in the system. We refer to this situation as a "systemic run".

For this decentralized allocation, a sufficient condition for a run is that the amount owed to all agents claiming to be early consumers is less than the resources available to meet these demands for each $\alpha^{0}$. For $\epsilon$ near zero, this is equivalent to $\phi\left(\alpha^{0}\right)<r^{E}\left(\alpha^{0}\right)$ for each $\alpha^{0}$. Since (2) is binding, $\pi<1$ implies $\phi\left(\alpha^{0}\right)<r^{E}\left(\alpha^{0}\right)$. In contrast to Diamond and Dybvig (1983), the condition for a run does not depend on the curvature of the utility function when the two period technology has essentially no liquidation value.

For $\epsilon<1$, but non-negligible, the conditions for a run are discussed in Cooper and Ross (1998). In this case, whether a run occurs or not depends on the contracted returns to early and late consumers and thus the portfolio choice of the bank. These choices depend, in part, on the risk aversion of the households as discussed in Cooper and Ross (1998).

Since our focus is on the consequence rather that the conditions for runs, we assume that the liquidation value and the household utility functions are such that a run can occur. Again, a sufficient condition for a run is that $\epsilon$ is close to zero.

\footnotetext{
${ }^{11}$ As in Cooper and Ross (1998), we could also study the choice of a deposit contract given that runs are possible. This is of interest if the government does not have an incentive to provide deposit insurance.
} 


\subsection{Responding to a Run}

In the event of a run, the paper is organized around two distinct forms of government intervention. The first is orderly liquidation and entails the (partial) liquidation of bank assets, undertaken by a regulator that manages the bank in the event of a run. As soon as a run is underway, i.e. the number of depositors served exceeds $\pi$, the regulator intervenes. The regulator controls the liquidation of bank assets as well as payments to non-served depositors. These payments are limited by the information of the regulator and the ability of depositors to mis-represent their taste types. The timing of decisions and choice problem of the regulator is made precise in Section 3.

The second government action, deposit insurance, denoted "DI", is undertaken by a Treasury that finances its provision through taxation. In this case, banks liquidate all of their illiquid assets, serve a fraction of early withdrawers and the Treasury eventually provides deposit insurance to the fraction of non-served depositors, funded by means of taxation. As developed in Section 4, this taxation creates the basis for redistribution and thus a cost to the provision of deposit insurance.

The distinction between the regulator and the Treasury is convenient for separating liquidation policy from the provision of deposit insurance. The responsibility of these actors are consistent with the structure of current banking regulation in the US. Under the Dodd-Frank regulations, the Orderly Liquidation Authority (OLA) controls the asset sales of failed financial institutions not covered by deposit insurance. This control is then broadened to include deposit insurance for banks covered by the FDIC. The funding for the FDIC, as needed, is provided by the taxation authority of the Treasury.

After understanding these two forms of intervention, the provision of deposit insurance along with regulation is presented in Section 5. Again, the focus is on the nature of the ex post intervention and its affect on the occurrence of bank runs.

\section{Orderly Liquidation}

This section studies the intervention by the regulator. ${ }^{12}$ By assumption, there is no deposit insurance.

Once the sum of the withdrawals exceeds the amount of liquid investment, the regulator is contacted and informed that a run is in process. The bank does not suspend convertibility unilaterally but instead effectively hands control of its operations to the regulator. Thus the decision to suspend convertibility is made optimally ex post, as in Ennis and Keister (2009). The analysis characterizes this intervention and provides conditions under which runs are prevented. While of interest in its own right, the analysis serves as a building block to the provision of deposit insurance and the control over liquidation studied in section 5 .

\footnotetext{
${ }^{12}$ It is closely related to Ennis and Keister (2009). In contrast to Ennis and Keister (2009), our regulator has the power to reset the obligations to early and late consumers, subject to incentive compatibility. Our regulator is not allowed to redistribute consumption across endowment types. This does not arise in Ennis and Keister (2009) as their agents are homogenous except for tastes.
} 
In response to a run, the regulator chooses the amount of long-term assets to liquidate and the revised allocations to depositors. Subject to incentive compatibility, the regulator separates the households into early and late types. ${ }^{13}$ The intervention is essentially an ex post reallocation of existing bank resources by a powerful regulator.

But there are some limits to this intervention. First, the regulator is unable to tax households to finance transfers to depositors. Thus any redistribution within a bank must be feasible without the infusion of outside resources. Second, the regulator is also unable to recapture the deposits received from the household served in the bank run. In this sense, the regulator is constrained by the sequential service of the bank.

To be clear, the timing and the regulator's problem is summarized as follows.

- The bank contacts the regulator when total withdrawals exceeds the liquid investment.

- The regulator chooses

- the optimal liquidation policy;

- the allocation of the bank assets to early and late depositors.

- The regulator is

- unable to transfer from depositors who have already been served;

- must offer an incentive compatible allocation.

\subsection{Optimal Liquidation Policy}

Specifically, the optimization problem of the regulator at the time of its intervention is to choose a liquidation policy, $Z\left(\alpha^{0}\right)$, as well as allocations to early and late households, denoted by $\left(\tilde{\chi}^{E}\left(\alpha^{0}\right), \tilde{\chi}^{L}\left(\alpha^{0}\right)\right)$, to maximize

$$
(1-\pi)\left[\int \omega\left(\alpha^{0}\right) \pi v\left(\bar{\alpha}+\tilde{\chi}^{E}\left(\alpha^{0}\right)\right) d F\left(\alpha^{0}\right)+\int \omega\left(\alpha^{0}\right)(1-\pi) v\left(\bar{\alpha}+\tilde{\chi}^{L}\left(\alpha^{0}\right)\right) d F\left(\alpha^{0}\right)\right] .
$$

The first term is the welfare of the early households and the second is for the late households. The fraction already served prior to the intervention of the regulator is $\pi$. So the objective and constraints are multiplied by the fraction not yet served. The weight for household of type $\alpha^{0}$, given by $\omega\left(\alpha^{0}\right)$, implies that some households receive relatively more weight than others in the social objective, perhaps reflecting political power.

For each $\alpha^{0}$, equivalently each bank, there are two resource constraints:

$$
(1-\pi) \pi \tilde{\chi}^{E}\left(\alpha^{0}\right)=\epsilon Z\left(\alpha^{0}\right), \text { and }
$$

\footnotetext{
${ }^{13}$ Here, in contrast, to the bank runs case there is no concern for multiplicity. The government offers a menu of allocations and the households self-select. The payments to each type are independent of the choices of others. Truth-telling is a dominant strategy.
} 


$$
(1-\pi)(1-\pi) \tilde{\chi}^{L}\left(\alpha^{0}\right)=\left[(1-\phi) \alpha^{0}-Z\left(\alpha^{0}\right)\right] R .
$$

Finally, there is an incentive compatibility condition:

$$
\tilde{\chi}^{L}\left(\alpha^{0}\right) \geq \tilde{\chi}^{E}\left(\alpha^{0}\right)
$$

so that late households prefer to reveal their type rather than claim to be early households.

In this problem, the regulator does not redistribute across wealth groups, despite the potential desirability of doing so. This is a consequence of imposing that the constraints (5) and (6) hold for each $\alpha^{0}$. So, in effect, (4), is solved for each $\alpha^{0}$, given (5) and (6). The incentive compatibility condition, (7), also holds for each $\alpha^{0}$.

Despite the lack of commitment, the expectation of the liquidation policy will, in some circumstances, prevent a bank run. Formally,

Proposition 2 If $\epsilon$ is sufficiently close to zero, then the optimal response of the regulator entails a limited liquidation of the illiquid investment. This intervention will prevent runs.

Proof. Substituting the constraints into (4), the first order condition with respect to $Z\left(\alpha^{0}\right)$ is

$$
\epsilon v^{\prime}\left(\bar{\alpha}+\tilde{\chi}^{E}\left(\alpha^{0}\right)\right)+\lambda^{Z}\left(\alpha^{0}\right)=R v^{\prime}\left(\bar{\alpha}+\tilde{\chi}^{L}\left(\alpha^{0}\right)\right) .
$$

Here $\lambda^{Z}\left(\alpha^{0}\right)$ is the multiplier on the constraint $Z\left(\alpha^{0}\right) \geq 0$. This condition ignores the incentive compatibility condition which is checked later.

Assume $\epsilon=0$, so there is no liquidation value. Then the solution to (4) must be $Z\left(\alpha^{0}\right)=0$. In this case, the left side of (6) is the total payout to the late households, $(1-\pi)^{2} \tilde{\chi}^{L}\left(\alpha^{0}\right)$. This equals the fraction of their deposits to the bank, multiplied by the return: $(1-\phi) \alpha^{0} R$. From the full-information allocation, $(1-\pi) \chi^{* L}\left(\alpha^{0}\right)=(1-\phi) \alpha^{0} R$. Hence $\tilde{\chi}^{L}\left(\alpha^{0}\right)>\chi^{* L}\left(\alpha^{0}\right)$. Since $\chi^{* L}\left(\alpha^{0}\right)>\chi^{* E}\left(\alpha^{0}\right)$ from the competitive equilibrium, $\tilde{\chi}^{L}\left(\alpha^{0}\right)>\chi^{* E}\left(\alpha^{0}\right)>0$. This last inequality implies that (7) holds.

Further, $\tilde{\chi}^{L}\left(\alpha^{0}\right)>\chi^{* E}\left(\alpha^{0}\right)$ implies that a late consumer would prefer not to be served and obtain the allocation coming from the solution to (4). Thus late households have no incentive to run.

By continuity, this logic applies for $\epsilon$ close to zero: the optimal reallocation prevents a run. Though once $\epsilon>0$, there will be some liquidations in the solution to (8).

This proposition indicates that runs are prevented by the optimal reallocation if the liquidation value is small. ${ }^{14}$ If the liquidation cost is not very large, then the regulator will optimally choose to undertake some liquidation.

The following proposition argues that the liquidation policy depends on the depositor's wealth levels. The result pertains to any $\epsilon>0$.

\footnotetext{
${ }^{14}$ Though Ennis and Keister (2009) stress the role of household risk aversion, it appears that a low liquidation value also prevents runs in their environment.
} 
Proposition 3 For $\epsilon>0$, the solution to (4) entails no liquidation for low values of $\alpha^{0}$ and positive liquidation for sufficiently high values of $\alpha^{0}$.

Proof. From (8), suppose there exists a value of $\alpha^{0}$, denoted $\tilde{\alpha}$ such that the non-negatively constraint on liquidation does not bind in the solution to (4) and liquidation equals zero: $\lambda^{Z}(\tilde{\alpha})=0$ and $Z(\tilde{\alpha})=0$. The first-order condition with respect to liquidation for this type would be

$$
v^{\prime}(\bar{\alpha}) \epsilon=R v^{\prime}\left(\bar{\alpha}+\frac{\chi^{* L}(\tilde{\alpha})}{1-\pi}\right)
$$

where, using (6), $\tilde{\chi}^{L}(\tilde{\alpha})=\frac{\chi^{* L}(\tilde{\alpha})}{1-\pi}$. Clearly $\tilde{\alpha}$ is monotonically increasing in $\frac{R}{\epsilon}$.

For $\alpha^{0}<\tilde{\alpha}$, the right side of (8) will be higher than the left side at $\alpha^{0}=\tilde{\alpha}$ since, from Proposition 1 , the consumption of late households is lower for lower $\alpha^{0}$. Thus $\lambda^{Z}\left(\alpha^{0}\right)>0$ for $\alpha^{0}<\tilde{\alpha}$ in order for (8) to hold.

If $\alpha^{0}>\tilde{\alpha}$, then the right side of (8) will be lower than at $\alpha^{0}=\tilde{\alpha}$. For (8) to hold, $Z\left(\alpha^{0}\right)>0$ and thus $\lambda^{Z}\left(\alpha^{0}\right)=0$ for $\alpha^{0}>\tilde{\alpha}$.

To see that the allocations are incentive compatible, for $\alpha^{0}<\tilde{\alpha}$ there are no liquidations and $\tilde{\chi}^{L}>0$ so late households have higher consumption than early ones. When there is liquidation, (8) holds. Since $\frac{R}{\epsilon}>1$, $\tilde{\chi}^{L}>\tilde{\chi}^{E}>0$ and the allocation is incentive compatible.

For $\tilde{\alpha}$ to be interior, we argue that (9) cannot hold for the bounds of the $\alpha^{0}$ distribution when that distribution is sufficiently dispersed. The link between the distribution of $\alpha^{0}$ and (9) comes from the fact, used earlier, that $\tilde{\chi}^{L}(\tilde{\alpha})=\frac{\chi^{* L}(\tilde{\alpha})}{1-\pi}$ for the critical value of $\alpha^{0}$ where $\lambda^{Z}(\tilde{\alpha})=0$ and $Z(\tilde{\alpha})=0$. The link between $\chi^{* L}(\tilde{\alpha})$ and $\tilde{\alpha}$ comes from the full information solution: as $\tilde{\alpha}$ increases so does $\chi^{* L}(\tilde{\alpha})$ in order for (3) to hold.

If the lower support of the $\alpha^{0}$ distribution is sufficiently small, then the right side of (9) will exceed the left side. If the upper support of the $\alpha^{0}$ distribution is sufficiently big, then the left side of (9) will exceed the right side. At neither of these extremes will (9) hold with equality. So, if the distribution of $\alpha^{0}$ is sufficiently dispersed in this sense, $\tilde{\alpha}$ will be interior.

Proposition 3, in contrast to Proposition 2, does not make a statement about preventing runs. For low values of $\alpha^{0}$, there are no liquidations. In that case, as shown in the proof to Proposition $3, \tilde{\chi}^{L}\left(\alpha^{0}\right)=\frac{\chi^{* L}\left(\alpha^{0}\right)}{1-\pi}$ which, from the full information solution, is bigger than $\chi^{* E}\left(\alpha^{0}\right)$. Thus for the low $\alpha^{0}$ households, the lack of liquidation protects investment for late households and thus prevents runs.

But for sufficiently high $\alpha^{0}$ households, the liquidation may reduce their consumption below the level, $\chi^{* E}\left(\alpha^{0}\right)$, obtained in a run. This depends on the magnitude of the liquidation which, from (8), depends on $\epsilon$. The following example illustrates how the magnitude of $\epsilon$ can determine if the liquidation eliminates a run or not. 
Figure 1: Runs Preventing Liquidation

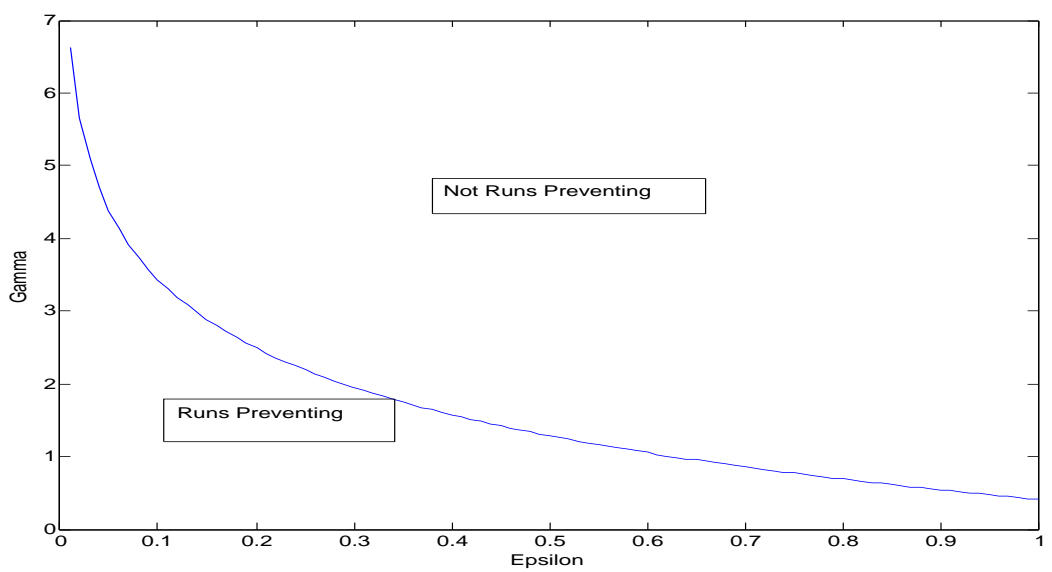

This figure shows combinations of $\gamma$ and $\epsilon$ such that $\tilde{\chi}^{L}=\chi^{* E}$. Below the curve, the intervention prevents runs.

\subsection{An Example}

Assume preferences are represented by a CRRA utility function, $v(c)=\frac{c^{1-\gamma}}{1-\gamma}$. We explore the combinations of $\gamma$ and $\epsilon$ such that the intervention of the regulator prevents a run. The analysis is for a given $\alpha^{0}$.

Figure 1 shows the inverse relationship between $\epsilon$ and the critical value of $\gamma$. Along the curve, the late households consumption level after the reallocation from liquidation equals the consumption of the early households: $\tilde{\chi}^{L}=\chi^{* E}$. Below this curve, the combination of $\epsilon$ and $\gamma$ implies that runs are prevented: $\tilde{\chi}^{L}>\chi^{* E}$.

Intuitively, for a given value of $\epsilon$, as $\gamma$ increases, $\chi^{* E}$ will increase as well to reduce $\frac{\chi^{* L}}{\chi^{* E}}$ in the full information allocation. This requires that $\phi$ increase to fund the higher consumption of early households. Consequently, the investment in the illiquid technology is lower and hence, all else the same, $\tilde{\chi}^{L}$ is lower. This combination of a higher $\chi^{* E}$ and a lower $\tilde{\chi}^{L}$ means that runs are not prevented for sufficiently high values of $\gamma$ given $\epsilon$.

This is one point where commitment enters the analysis. When there is no commitment to the magnitude of liquidation, the incentive to liquidate may be strong to drive the consumption of late households below that of households who are served at the start of the run. Thus the liquidation is optimal ex post but does not prevent a run. Ex ante the regulator might have chosen to commit to less liquidation in order to prevent 
runs. That policy is not followed in the absence of commitment.

Recall that the bank is not allowed to suspend convertibility unilaterally. Instead, at the point the bank would have suspended it instead contacts the regulator. We think this is reasonable for two reasons. First, it is hard to imagine a bank suspending withdrawals unilaterally in the current regulatory environment. Second, the regulator could impose the same suspension policy as the bank. If it chooses not to, as shown in Proposition 3, it is clear that suspension by a bank is dominated.

This result has important implications for the regulator's interventions. Though the liquidation decision may be optimal ex post, the redistribution may reduce the returns of late households enough that they choose to participate in the run. In this sense, the policy of orderly liquidation alone may be insufficient to resolve the fragility of the intermediation process. Of course, the regulator might promise ex ante to limit these liquidations, but that promise is not credible without commitment.

\section{Deposit Insurance}

In the previous section, a regulator controlled the liquidation decision of the bank and was able to redistribute the bank's resources only across depositors of the same endowment type at that bank. The regulator had no access to tax revenues to supplement the illiquid investment of the bank.

In this section, we study the response to a run from a very different perspective. Our focus is on the conditions under which deposit insurance is provided ex post, that is after a run, and funded through the taxation power of a Treasury. Thus there are resources available here that were not present in the regulator's problem.

As before, when a run is underway, the bank informs the Treasury that it has served $\pi$ early households and others are demanding their deposits. In contrast to the OLA discussion, the Treasury is unable to control the liquidation decision of the bank. Further, there is, by assumption, no suspension at the bank level. If there is a run, the bank meets the demands of depositors until its resource, both liquid and liquidated illiquid investments, are exhausted. At this point, the Treasury has the authority to provide deposit insurance.

We ask two questions. First, will deposit insurance be provided by the Treasury? If so, will it be sufficient to prevent a run? A positive answer to this latter question a very strong result as we have assumed a lack of commitment by public authorities and thus ruled out any ex ante actions by regulators to prevent a run. Further, we have assumed the deposit contract takes a very simple form, in effect ignoring the prospect of a run. So, if the deposit insurance is provided and negates incentives to run, the inability of the authorities to limit liquidation is inconsequential and the simple deposit contract is optimal.

Whether deposit insurance is provided will depend on the tax system that is used to finance these flows. A key issue is the redistributive effects of deposit insurance and the taxation needed to fund these transfers.

We first describe household welfare when deposit insurance is provided and when it is not. We then characterize the conditions under which deposit insurance increases social welfare and thus when it will be provided ex post. 
Throughout, the provision of deposit insurance is assumed to be complete. However, the structure of the tax system to fund these transfers is an object of the analysis. In this way, the net flow to the depositors is endogenous.

To be clear, the timing and the Treasury's problem is summarized as follows.

- The bank contacts the Treasury when total withdrawals exceeds the liquid investment.

- The Treasury

- does not limit the liquidation of the bank's assets;

- decides whether to provide deposit insurance or not;

- taxes households to fund the provision of any deposit insurance.

\subsection{Household Welfare}

If ex post the government provides deposit insurance in the event of a run by all households, leading to full liquidation of the illiquid investment, social welfare is:

$$
W^{D I}=\int \omega\left(\alpha^{0}\right) v\left(\bar{\alpha}+\chi^{* E}\left(\alpha^{0}\right)-T\left(\alpha^{0}\right)\right) f\left(\alpha^{0}\right) d \alpha^{0}
$$

where $\chi^{* E}\left(\alpha^{0}\right)$ is the total promised by the bank to an early household of type $\alpha^{0}$. In this expression, $\omega\left(\alpha^{0}\right)$ is again the weight in the social welfare function given to a type $\alpha^{0}$ household.

If $\omega\left(\alpha^{0}\right)$ is a constant, then the objective of the government is just a population weighted average of household expected utility. In general, the structure of $\omega\left(\alpha^{0}\right)$ will be relevant for gauging the costs and benefits of the redistribution associated with DI.

Another key element in the redistribution is the tax system used to pay for DI. In (10), $T\left(\alpha^{0}\right)$ is the tax paid by an agent of type $\alpha^{0}$. Government budget balance requires

$$
\int\left(T\left(\alpha^{0}\right)+\left[\phi\left(\alpha^{0}\right)+\left(1-\phi\left(\alpha^{0}\right)\right) \epsilon\right] \alpha^{0}\right) f\left(\alpha^{0}\right) d \alpha^{0}=\int \chi^{* E}\left(\alpha^{0}\right) f\left(\alpha^{0}\right) d \alpha^{0} .
$$

The left-hand side of this expression is the total tax revenues collected by the government plus the sum of the liquid investment and the liquidated value of the illiquid investment. The right-hand side is the total paid to depositors.

This specification of the tax burden assumes that all households are taxed, not just those who were not served during the bank run. While the banking activities of households may be constrained by sequential service, the government is assumed to have the ability to directly tax the endowment of households, as in $T\left(\alpha^{0}\right)$.

If, ex post, there is a bank run without any government intervention, then social welfare is given by:

$$
W^{N I}=\int \omega\left(\alpha^{0}\right)\left[\zeta v\left(\bar{\alpha}+\chi^{* E}\left(\alpha^{0}\right)\right)+(1-\zeta) v(\bar{\alpha})\right] d F\left(\alpha^{0}\right) .
$$


Here $\zeta$ is the probability a household obtains the full return on its deposit at a representative bank under sequential service. As all households are assumed to be served with equal probability,

$$
\zeta=\frac{\left.\int\left[\phi\left(\alpha^{0}\right)+\left(1-\phi\left(\alpha^{0}\right)\right) \epsilon\right] \alpha^{0}\right) f\left(\alpha^{0}\right) d \alpha^{0}}{\int \chi^{* E}\left(\alpha^{0}\right) f\left(\alpha^{0}\right) d \alpha^{0}} .
$$

The welfare values with and without DI are both calculated at the start of period 1 . This is because the government lacks the ability to commit to DI before agents make deposit decisions. The government can only react to an actual bank run in period 1 .

\subsection{Welfare Effects of DI}

The government has an incentive to provide deposit insurance iff $\Delta \equiv W^{D I}-W^{N I} \geq 0$. We can write this difference as

$$
\begin{array}{r}
\Delta=\int \omega\left(\alpha^{0}\right)\left[v\left(\chi^{* E}\left(\alpha^{0}\right)+\bar{\alpha}-T\left(\alpha^{0}\right)\right)-v\left(\chi^{* E}\left(\alpha^{0}\right)+\bar{\alpha}-\bar{T}\right)\right] f\left(\alpha^{0}\right) d \alpha^{0}+ \\
\int \omega\left(\alpha^{0}\right)\left[v\left(\chi^{* E}\left(\alpha^{0}\right)+\bar{\alpha}-\bar{T}\right)-v\left(\zeta \chi^{* E}\left(\alpha^{0}\right)+\bar{\alpha}\right)\right] f\left(\alpha^{0}\right) d\left(\alpha^{0}\right)+ \\
\int \omega\left(\alpha^{0}\right)\left[v\left(\zeta \chi^{* E}\left(\alpha^{0}\right)+\bar{\alpha}\right)-\zeta v\left(\chi^{* E}\left(\alpha^{0}\right)+\bar{\alpha}\right)-(1-\zeta) v(\bar{\alpha})\right] f\left(\alpha^{0}\right) d \alpha^{0}
\end{array}
$$

where $\bar{T}=\int T\left(\alpha^{0}\right) f\left(\alpha^{0}\right) d \alpha^{0}$.

Here there are three terms. The first two terms capture the two types of redistribution through deposit insurance. One effect is through differences in tax obligations and the other effect comes from differences in deposit levels across types. The third term is the insurance effect of deposit insurance.

Specifically, the first term captures the redistribution from taxes. It is the utility difference between consumption with deposit insurance and type dependent taxes and consumption with deposit insurance and type independent taxes, $\bar{T}$.

The second term captures the effects of redistribution through deposit insurance. The term $v\left(\chi^{* E}\left(\alpha^{0}\right)+\right.$ $\bar{\alpha}-\bar{T})-v\left(\zeta \chi^{* E}\left(\alpha^{0}\right)+\bar{\alpha}\right)$ is the difference in utility between the consumption allocation if a type $\alpha^{0}$ household gets his promised allocation and bears a tax of $\bar{T}$ and the allocation obtained if all households received a fraction $\zeta$ of their promised allocation. This second part is the utility of the expected consumption if there are runs without deposit insurance.

The third term captures the insurance gains from DI. It is clearly positive if $v(c)$ is strictly concave. These gains are independent of the shape of $\omega\left(\alpha^{0}\right)$.

The key trade-off to the provision of DI ex post is whether the insurance gains dominate the redistribution effects. The insurance gains are apparent if there is no heterogeneity across households, so $F\left(\alpha^{0}\right)$ is degenerate. In this case, deposit insurance is valued as it provides risk sharing across households of the uncertainty coming from sequential service.

Proposition 4 If $F\left(\alpha^{0}\right)$ is degenerate, $v(c)$ is strictly concave, then the government will have an incentive to provide deposit insurance. 
Proof. In this case, the first two terms of (14) are zero. The third term is strictly positive since $v(\cdot)$ is strictly concave. Hence $\Delta>0$.

This is parallel to the standard interpretation of the Diamond and Dybvig (1983) model although it obtains here without commitment. It highlights the insurance gain from DI when there are no costs of redistribution. Here the insurance benefit is enough to motivate the provision of deposit insurance without commitment.

When there is heterogeneity across households, these insurance gains may be offset by redistribution costs. In the next two subsections, we consider two situations. In the first one, the tax system to fund DI is set at the same time the decision is made to provide DI or not. In this case, there is enough flexibility in the tax system to offset any redistribution effects of DI. In the second scenario, we take the tax system as given and explore the incentives to provide DI.

\subsection{Optimal Taxation: DI Will be Provided}

Consider a government which can choose the tax system used to finance DI at the same time it is choosing to provide insurance or not. This can be interpreted as the choice of a supplemental tax to fund DI.

In this setting, $W^{D I}$ is the solution to an optimal tax problem:

$$
W^{D I}=\max _{T\left(\alpha^{0}\right)} \int \omega\left(\alpha^{0}\right) v\left(\chi^{* E}\left(\alpha^{0}\right)+\bar{\alpha}-T\left(\alpha^{0}\right)\right) f\left(\alpha^{0}\right) d \alpha^{0}
$$

subject to a government budget constraint (11). The first-order condition implies that $\omega\left(\alpha^{0}\right) v^{\prime}\left(\chi^{* E}\left(\alpha^{0}\right)+\right.$ $\left.\bar{\alpha}-T\left(\alpha^{0}\right)\right)$ independent of $\alpha^{0}$. This creates a connection between $\omega\left(\alpha^{0}\right)$ and $T\left(\alpha^{0}\right)$ which can be used to evaluate the gains to DI.

Proposition 5 If $T\left(\alpha^{0}\right)$ solves the optimization problem (15), then deposit insurance is always provided.

\section{Proof.}

Using the first-order condition from (15), we rewrite (14) as:

$$
\begin{gathered}
\Delta=\int \frac{\left[v\left(\chi^{* E}\left(\alpha^{0}\right)+\bar{\alpha}-T\left(\alpha^{0}\right)\right)-v\left(\zeta \chi^{* E}\left(\alpha^{0}\right)+\bar{\alpha}\right)\right]}{v^{\prime}\left(\chi^{* E}\left(\alpha^{0}\right)+\bar{\alpha}-T\left(\alpha^{0}\right)\right)} f\left(\alpha^{0}\right) d\left(\alpha^{0}\right)+ \\
\int \omega\left(\alpha^{0}\right)\left[v\left(\zeta \chi^{* E}\left(\alpha^{0}\right)+\bar{\alpha}\right)-\zeta v\left(\chi^{* E}\left(\alpha^{0}\right)+\bar{\alpha}\right)-(1-\zeta) v(\bar{\alpha})\right] f\left(\alpha^{0}\right) d \alpha^{0}
\end{gathered}
$$

The second term is positive as argued previously. The first term can be shown to be positive as well.

To see this, do a second-order approximation of the second part of the first term, $v\left(\zeta \chi^{* E}\left(\alpha^{0}\right)+\bar{\alpha}\right)$, around the first part, $v\left(\chi^{* E}\left(\alpha^{0}\right)+\bar{\alpha}-T\left(\alpha^{0}\right)\right)$. Using the fact that $\int T\left(\alpha^{0}\right) f\left(\alpha^{0}\right) d \alpha^{0}=(1-\zeta) \int \chi^{* E}\left(\alpha^{0}\right) f\left(\alpha^{0}\right) d \alpha^{0}$, the first term reduces to

$$
\int \frac{-\left((1-\zeta) \chi^{* E}\left(\alpha^{0}\right)-T\left(\alpha^{0}\right)\right)^{2} v^{\prime \prime}\left(\chi^{* E}\left(\alpha^{0}\right)+\bar{\alpha}-T\left(\alpha^{0}\right)\right)}{v^{\prime}\left(\chi^{* E}\left(\alpha^{0}\right)+\bar{\alpha}-T\left(\alpha^{0}\right)\right)} f\left(\alpha^{0}\right) d\left(\alpha^{0}\right)
$$


which is positive as $v(\cdot)$ is strictly concave. Thus $\Delta>0$.

Why is there always a gain to deposit insurance here? Because with this ex post tax scheme, the current government can undo any undesirable redistribution coming from DI. Thus the redistribution costs are not present.

This result is important for the design of policy. As governments strive to make clear the conditions under which deposit insurance and other financial bailouts will be provided ex post, they ought to articulate how revenues will be raised to finance those transfers. If a government says it will not rely on existing tax structures but instead will, in effect, solve (15), then private agents will know that the government will have enough flexibility in taxation to overcome any redistributive costs of deposit insurance. This will enhance the credibility of a promise to provide deposit insurance ex post.

This intervention will (weakly) prevent a run. Along this path, all agents receive $\chi^{* E}\left(\alpha^{0}\right)$, whether they ran and were served by the bank directly or were later served by the deposit authorities.

\subsection{Type Independent Taxes: DI May Not be Provided}

In some cases, a government may not have the flexibility due to time lags and political obstacles to levy a special tax to fund a bailout. Instead, the use of general tax revenues may be required, leading to additional taxation to fund existing government spending. If the tax system to fund DI is not set ex post, costly redistribution may arise. Then the trade-off between insurance gains and redistribution costs emerges. As we shall see, these redistribution effects can be large enough to offset insurance gains.

To study these issues, we return to (14) which cleanly distinguishes the redistribution and insurance effects. We start with a case in which taxes are independent of type to gain some understanding of the trade-off and then return to the more general case where taxes depend on agent types.

To focus on one dimension of the redistributive nature of deposit insurance, assume that taxes are type independent: $T\left(\alpha^{0}\right)=\bar{T}$ for all $\alpha^{0}$. Under this tax system, (14) simplifies to:

$$
\begin{gathered}
\Delta=\int \omega\left(\alpha^{0}\right)\left[v\left(\chi^{* E}\left(\alpha^{0}\right)-\bar{T}+\bar{\alpha}\right)-v\left(\zeta \chi^{* E}\left(\alpha^{0}\right)+\bar{\alpha}\right)\right] f\left(\alpha^{0}\right) d\left(\alpha^{0}\right)+ \\
\int \omega\left(\alpha^{0}\right)\left[v\left(\zeta \chi^{* E}\left(\alpha^{0}\right)+\bar{\alpha}\right)-\zeta v\left(\chi^{* E}\left(\alpha^{0}\right)+\bar{\alpha}\right)-(1-\zeta) v(\bar{\alpha})\right] f\left(\alpha^{0}\right) d \alpha^{0} .
\end{gathered}
$$

If taxes are independent of type, then the government budget constraint implies

$$
\bar{T}=\int\left(\chi^{* E}\left(\alpha^{0}\right)-\left[\phi\left(\alpha^{0}\right)+\left(1-\phi\left(\alpha^{0}\right)\right) \epsilon\right] \alpha^{0}\right) f\left(\alpha^{0}\right) d \alpha^{0} .
$$

With type independent taxes, redistribution arises solely from differences in deposits across types. In some cases, this redistribution can be costly to society. The next two propositions require the additional restriction on $v(\cdot)$, mentioned earlier, that $\zeta v^{\prime}(\zeta c+\bar{\alpha})$ is increasing in $\zeta$.

Proposition 6 If $\omega\left(\alpha^{0}\right)$ is weakly decreasing in $\alpha^{0}$, then the redistribution effect of deposit insurance reduces social welfare. 
Proof. The effect of redistribution is captured by the first term in (17). Using $\zeta$ from (13), $\bar{T}=$ $(1-\zeta) \int \chi^{* E}(\alpha) f(\alpha) d \alpha$. Letting $\hat{c}\left(\alpha^{0}\right)=\zeta \chi^{* E}\left(\alpha^{0}\right)+\bar{\alpha}$ and $\bar{c} \equiv \int \hat{c}\left(\alpha^{0}\right) f\left(\alpha^{0}\right) d \alpha^{0}$, the first term in (17) becomes

$$
\int \omega\left(\alpha^{0}\right)\left[v\left(\frac{1}{\zeta}\left(\hat{c}\left(\alpha^{0}\right)-\bar{c}\right)+\bar{c}\right)-v\left(\hat{c}\left(\alpha^{0}\right)\right)\right] f\left(\alpha^{0}\right) d \alpha^{0} .
$$

The first consumption allocation, $\frac{1}{\zeta}\left(\hat{c}\left(\alpha^{0}\right)-\bar{c}\right)+\bar{c}$, is a mean-preserving spread of the second, $\hat{c}\left(\alpha^{0}\right)$. Both have the same mean of $\bar{c}$ and since $1>\zeta$ the variance of the first consumption allocation is larger. From the results on mean-preserving spreads, if $v(c)$ is strictly concave

$$
\int\left[v\left(\chi^{* E}\left(\alpha^{0}\right)-\bar{T}+\bar{\alpha}\right)-v\left(\zeta \chi^{* E}\left(\alpha^{0}\right)+\bar{\alpha}\right)\right] f\left(\alpha^{0}\right) d\left(\alpha^{0}\right)<0
$$

Using the fact that the welfare weights integrate to one, we can write the first term in (17) as

$$
\begin{array}{r}
\int\left[v\left(\chi^{* E}\left(\alpha^{0}\right)-\bar{T}+\bar{\alpha}\right)-v\left(\zeta \chi^{* E}\left(\alpha^{0}\right)+\bar{\alpha}\right)\right] f\left(\alpha^{0}\right) d\left(\alpha^{0}\right)+ \\
\left.\operatorname{cov}\left(\omega\left(\alpha^{0}\right), v\left(\chi^{* E}\left(\alpha^{0}\right)-\bar{T}+\bar{\alpha}\right)-v\left(\zeta \chi^{* E}\left(\alpha^{0}\right)+\bar{\alpha}\right)\right)\right) .
\end{array}
$$

From the discussion above, the first term is negative. If $\omega\left(\alpha^{0}\right)$ is independent of $\alpha^{0}$, then the covariance term in (21) is zero and so (21) is negative. This corresponds to costly redistribution.

If $\omega\left(\alpha^{0}\right)$ is decreasing in $\alpha^{0}$, then social welfare puts less than the population weight on high $\alpha^{0}$ agents. The difference, $v\left(\chi^{* E}\left(\alpha^{0}\right)-\bar{T}+\bar{\alpha}\right)-v\left(\zeta \chi^{* E}\left(\alpha^{0}\right)+\bar{\alpha}\right)$ in (21) is increasing in $\alpha^{0}$. This follows from the assumption that $\zeta v^{\prime}(\zeta c+\bar{\alpha})$ is increasing in $\zeta$ and the fact that $\chi^{* E}\left(\alpha^{0}\right)$ is monotonically increasing from Proposition 1. As a consequence, the covariance term in (21) is negative. Thus the redistribution effect reduces welfare if either $\omega\left(\alpha^{0}\right)$ is either independent of, or decreasing in, $\alpha^{0}$.

Proposition 6 makes clear that the provision of DI may entail distribution effects that are socially undesirable. There are two key pieces of the argument. First, if welfare weights are type independent, then the provision of deposit insurance financed by a lump-sum tax creates a mean preserving spread in consumption. This is welfare reducing. Second, if welfare weights are decreasing so that the rich are valued less than the poor in the social welfare function, then the redistribution from poor to rich from the provision of deposit insurance reduces social welfare further. This second influence is captured by the covariance term in (21).

This result contrasts with Proposition 4 which eliminates the redistribution issue and thus highlights the gains from the provision of deposit insurance. One important factor in the trade-off between insurance and redistribution is the underlying distribution of social (political) weights.

Proposition 7 If $\omega\left(\alpha^{0}\right)$ is sufficiently increasing in $\alpha^{0}$, then deposit insurance is provided. Further, if $\omega\left(\alpha^{0}\right)$ is sufficiently decreasing in $\alpha^{0}$ and households are not too risk averse, then deposit insurance is not provided.

Proof. Let $\Omega\left(\alpha^{0}\right) \equiv v\left(\chi^{* E}\left(\alpha^{0}\right)-\bar{T}+\bar{\alpha}\right)-v\left(\zeta \chi^{* E}\left(\alpha^{0}\right)+\bar{\alpha}\right)$. This is contained in the first term of (17). By the assumption that $\zeta v^{\prime}(\zeta c+\bar{\alpha})$ is increasing in $\zeta$, using $\bar{T}>0$ and $\chi^{* E}\left(\alpha^{0}\right)$ is increasing in $\alpha^{0}$, $\Omega^{\prime}\left(\alpha^{0}\right)=\left[v^{\prime}\left(\chi^{* E}\left(\alpha^{0}\right)-\bar{T}+\bar{\alpha}\right)-\zeta v^{\prime}\left(\zeta \chi^{* E}\left(\alpha^{0}\right)+\bar{\alpha}\right)\right] \chi^{* E^{\prime}}\left(\alpha^{0}\right)>0$. 
Using the construction in the proof of Proposition 6, there exists $\tilde{\alpha}$ such that $\zeta \chi^{* E}(\tilde{\alpha})+\bar{\alpha}=\bar{c}$ and therefore $\Omega(\tilde{\alpha})=0$. Thus for $\alpha^{0}>\tilde{\alpha}, \Omega\left(\alpha^{0}\right)>0$.

If $\omega\left(\alpha^{0}\right)$ is sufficiently large for $\alpha^{0} \geq \tilde{\alpha}$ and sufficiently close to zero for $\alpha^{0}<\tilde{\alpha}$, then the first term in (17) is positive and thus $\Delta$ is positive. In this case, there are both insurance and redistributive gains from the provision of DI.

By a similar logic, for $\alpha^{0}<\tilde{\alpha}, \Omega\left(\alpha^{0}\right)<0$. If $\omega\left(\alpha^{0}\right)$ is sufficiently large for $\alpha^{0} \leq \tilde{\alpha}$ and sufficiently small for $\alpha^{0} \geq \tilde{\alpha}$, then the first term in (17) is negative. If households are not too risk adverse insurance gains will be small. Given these small insurance gains, there will exist welfare weights such that $\Delta$ will be negative.

These propositions highlight the redistributive effects of deposit insurance. Proposition 6 provides sufficient conditions for redistribution to be costly. Proposition 7 makes clear that the effects of redistribution depend on the distribution of weights in the social objective function. If the rich are weighted heavily enough, the redistribution from deposit insurance is a gain rather than a cost. Then deposit insurance will be provided.

Else, as in the second part of Proposition 7, the redistribution may be so undesirable that it dominates insurance gains. In this case, deposit insurance will not be provided.

To gauge the magnitude of these effects, we turn to an example. The example illustrates that for low degrees of risk aversion, so that insurance gains are small, deposit insurance will not be provided.

\subsubsection{Highlighting the Trade-off Between Insurance and Redistribution}

This section further clarifies the trade-off between insurance gains and redistribution from the deposit insurance. It does so first by working through an example and second by studying the allocation from a contract further restricted by information asymmetries. Here we retain the assumption of lump-sum taxation.

Example Here we consider a specific example to illustrate conditions for the provision of deposit insurance. Assume there are two types of households, rich and poor. The rich households have an endowment in youth of $\alpha^{0}=\alpha^{r}$ and the poor have an endowment in youth of $\alpha^{0}=\alpha^{p}$. Let the fraction of rich households be given by $f$. Assume $u(c)=\frac{c^{1-\gamma_{0}}}{1-\gamma_{0}}$ and that $v(c)=\beta \frac{c^{1-\gamma_{1}}}{1-\gamma_{1}}$. Thus there are two curvature parameters, $\gamma_{0}$ and $\gamma_{1}$. Throughout this example, we set $\gamma_{0}=2$. The value of liquidation is assumed to be negligible so that an equilibrium with runs exists.

To compute an equilibrium, we solve for the optimal contract offered by a bank to a type $\alpha^{0}$ household. This involves finding interest rates for early and late consumers that satisfy (2) and (3). Further, bank investment in each of the two technologies must be non-negative and interest rates must be non-negative as well.

Given the contract, we can evaluate the social gains from deposit insurance by calculating $\Delta \equiv W^{D I}-$ $W^{N I}$ using some welfare weights. Taxes are type independent. 


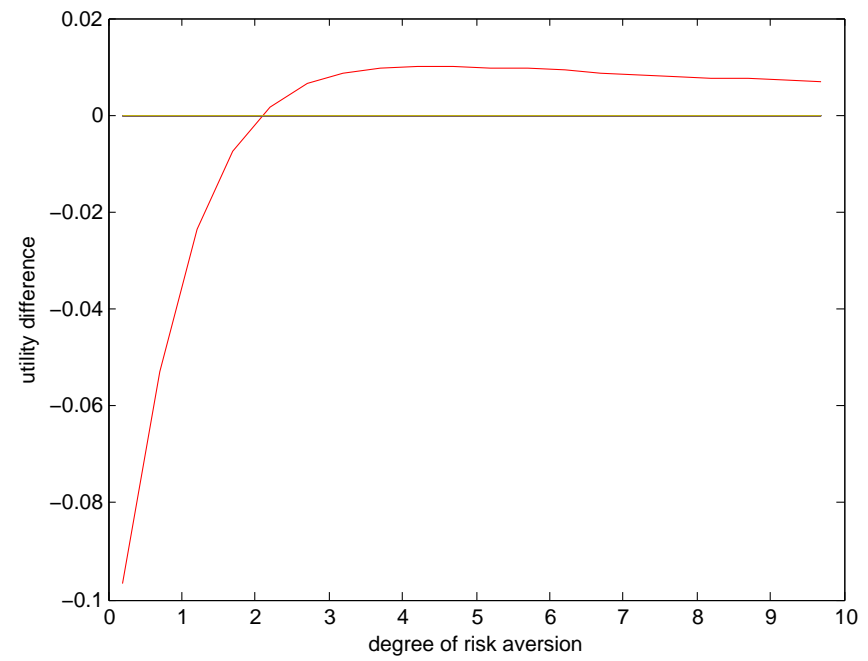

Figure 2: Effects of Risk Aversion

Figures 2 and 3 provide some results. For these figures, $\bar{\alpha}=1, \beta=0.9, R=1.10$ and the fraction of rich households was set at $50 \%$. The utility difference from the provision of deposit insurance, $\Delta$, is shown on the vertical axis.

The effects of variation in risk version, $\gamma_{1}$, in $v(\cdot)$ are shown in Figure 2. Here the initial endowments were fixed at $\alpha^{p}=3$ and $\alpha^{r}=5$. The welfare weight for the poor is 0.80 , larger than their population share.

For low values of risk aversion, the net gains to the provision of deposit insurance are negative. That is, the costs of redistribution offset the insurance gains. The utility difference increases as $\gamma_{1}$ increases and eventually becomes positive. Interestingly, for high enough values of $\gamma_{1}$, the utility gains from deposit insurance again start to fall off as the costs of redistribution become stronger.

Figure 3 studies the effects of income distribution on the gains from deposit insurance. On the horizontal axis is the welfare weight placed on poor households. One curve is the base case and the second, steeper, curve comes from a mean-preserving spread of endowments such that $\alpha^{p}=2.8$ and $\alpha^{r}=5.2$. This is the case labelled "MPS" in the figure. The curvature of $v(\cdot)$ was set at $\gamma_{1}=2$.

As is clear from this figure, the MPS of endowments reduces the gains to DI for all levels of the welfare weight for the poor below around $20 \%$. The reason is that the spread of the endowments exacerbates the redistribution costs of the provision of deposit insurance. Only when the poor have a low welfare weight, does the redistribution in favor of the rich, combined with the provision of insurance, increase social welfare. After the MPS in endowments, if the weight on the poor exceeds 0.7, then deposit insurance will not be provided. This compares to a critical weight of about 0.8 in the baseline case. 


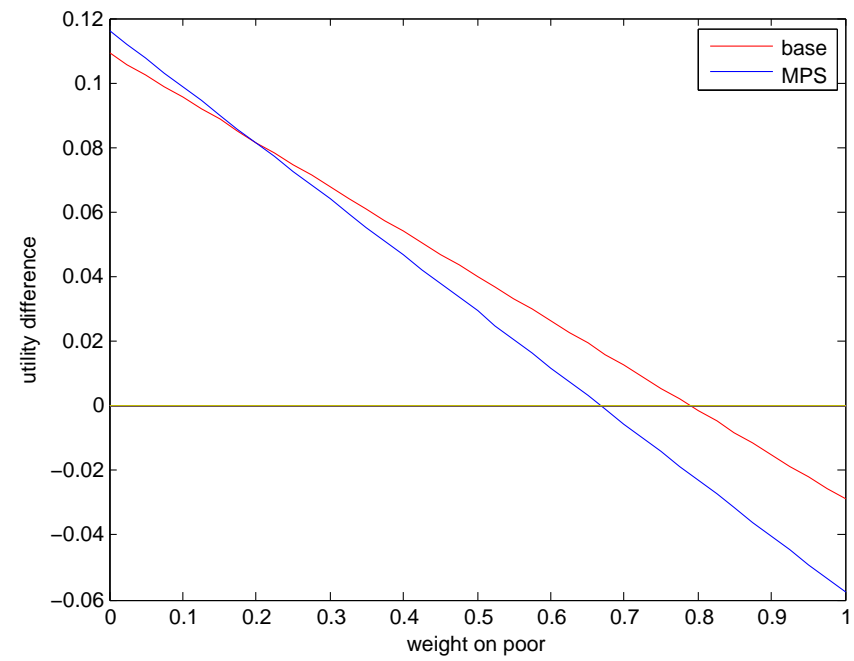

Figure 3: MPS on Endowment Distribution

Restricted Contract A second way of highlighting the trade-off between redistribution and insurance is through the outcome of the model with a restricted contract. In particular, assume that the bank is restricted to offer the same contract to all agents: type dependent returns are not feasible. Further, suppose that a deposit contract is summarized by a single interest rate, denoted $r$, which is the annual gross return. So deposits for one period earn $r$ and deposits for two periods earn $r^{2}$.

With this simplified contract we continue to explore the trade-off between redistribution and insurance. The analysis of the household and banking problems with this restricted contract are similar to the more general case specified above.

With this simple contract, even if $v^{\prime \prime}(c)=0$, the household will have well defined consumption levels in both periods as long as $u^{\prime \prime}(c)<0$. Thus we can study the special case of risk neutrality in periods 1 and 2 in this model. In the previous specification where the returns could differ for early and late consumers, at $v^{\prime \prime}(\cdot)=0$, consumption for early households went to zero. The restricted contract has the benefit of being better behaved when $v(\cdot)$ is linear.

A bank will choose a return $r$ and a portfolio to maximize expected utility of the households subject to zero profit and feasibility constraints. This is analogous to the problem specified above, though with a much simpler contract.

Using this model, we return to our discussion of costly redistribution and the risk sharing benefits of deposit insurance. For the restricted contract, if households are almost risk neutral with respect to variations in early and late consumptions, DI will not be provided ex post if redistribution is costly enough. 
Proposition 8 If households are not too risk averse and $\omega\left(\alpha^{0}\right)$ is strictly decreasing in $\alpha^{0}$, then a government will not have an incentive to provide deposit insurance.

\section{Proof.}

With the restricted contract, (17) becomes

$$
\begin{gathered}
\Delta=\int \omega\left(\alpha^{0}\right)\left[v\left(r \alpha^{0}-\bar{T}+\bar{\alpha}\right)-v\left(\zeta r \alpha^{0}+\bar{\alpha}\right)\right] f\left(\alpha^{0}\right) d\left(\alpha^{0}\right)+ \\
\int \omega\left(\alpha^{0}\right)\left[v\left(\zeta r \alpha^{0}+\bar{\alpha}\right)-\zeta v\left(r \alpha^{0}+\bar{\alpha}\right)-(1-\zeta) v(\bar{\alpha})\right] f\left(\alpha^{0}\right) d \alpha^{0} .
\end{gathered}
$$

Suppose $v(\cdot)$ is linear. Then there are no insurance gains and the second term in (22) is zero, and therefore

$$
\Delta=\int \omega\left(\alpha^{0}\right)\left[(1-\zeta) r \alpha^{0}-\bar{T}\right] f\left(\alpha^{0}\right) d\left(\alpha^{0}\right) .
$$

Using $\zeta=\frac{\left.\int\left(\phi\left(\alpha^{0}\right)+\left(1-\phi\left(\alpha^{0}\right)\right) \epsilon\right)\right] f\left(\alpha^{0}\right) d \alpha^{0}}{\int r \alpha^{0} f\left(\alpha^{0}\right) d \alpha^{0}}, \bar{T}=(1-\zeta) r \int \alpha^{0} f\left(\alpha^{0}\right) d \alpha^{0}$. Let $\bar{d} \equiv \int \alpha^{0} f\left(\alpha^{0}\right) d \alpha^{0}$ be total deposits, then (24) becomes

$$
\begin{array}{r}
(1-\zeta) r \int \omega\left(\alpha^{0}\right)\left[\left(\alpha^{0}-\bar{d}\right)\right] f\left(\alpha^{0}\right) d\left(\alpha^{0}\right)= \\
(1-\zeta) r \times \operatorname{cov}\left(\omega\left(\alpha^{0}\right), \alpha^{0}-\bar{d}\right) .
\end{array}
$$

The provision of deposit insurance redistributes from low to high $\alpha^{0}$ households. This redistribution reduces social welfare if $\omega\left(\alpha^{0}\right)$ is strictly decreasing.

If $v(\cdot)$ is close enough to linearity, then the insurance gain from deposit insurance, the second term in (22) can be made arbitrarily small. Thus the insurance gains are dominated by the costs of redistribution when $\omega\left(\alpha^{0}\right)$ is strictly decreasing.

This proposition highlights the redistributive aspect of DI. Since the total resources in the economy are predetermined and agents are nearly risk neutral, the only role of DI is to redistribute consumption. The nature of that redistribution depends on the endowments of each type $\alpha^{0}$ and the tax system. The social value of the redistribution is determined by $\omega\left(\alpha^{0}\right)$. When this is decreasing, so that the rich households have a lower weight and households are not very risk averse, then DI will not be provided ex post.

\subsection{Partial Deposit Insurance}

Here we consider limiting the level of deposit insurance to households so that the fraction of deposits insured would be lower for higher wealth households. To be clear, all households will receive some insurance, but the insurance is capped ex post. This policy may have value when the redistribution from poor to rich households from full DI is socially undesirable.

Specifically, for those not served in the run, insurance would be set as: $\tilde{\chi}^{E}\left(\alpha^{0}\right)=\min \left(\chi^{* E}\left(\alpha^{0}\right), \chi^{* E}\left(\alpha^{*}\right)\right)$. In this case, the value of deposit insurance, as a function of the cut-off $\alpha^{*}$, is 


$$
\begin{array}{r}
W^{D I}\left(\alpha^{*}\right)=\int_{\alpha_{-}}^{\alpha^{*}} \omega\left(\alpha^{0}\right) v\left(\bar{\alpha}+\chi^{* E}\left(\alpha^{0}\right)-\bar{T}\right) d F\left(\alpha^{0}\right)+ \\
\int_{\alpha^{*}}^{\alpha_{+}} \omega\left(\alpha^{0}\right)\left[(1-\zeta) v\left(\bar{\alpha}+\chi^{* E}\left(\alpha^{*}\right)-\bar{T}\right)+\zeta v\left(\bar{\alpha}+\chi^{* E}\left(\alpha^{0}\right)-\bar{T}\right)\right] d F(\alpha)
\end{array}
$$

where $\chi^{* E}\left(\alpha^{*}\right)$ is the payout to early $\alpha^{*}$ types and is the limit to payments. The first term is the utility of households with $\alpha^{0} \leq \alpha^{*}$ who receive full insurance. The second and third terms apply to households with $\alpha^{0}>\alpha^{*}$ who either receive partial DI or were served during the run.

For this formulation, the tax must satisfy

$$
\bar{T}=(1-\zeta)\left[\int_{\alpha_{-}}^{\alpha^{*}} \chi^{* E}\left(\alpha^{0}\right) d F\left(\alpha^{0}\right)+\left(1-F\left(\alpha^{*}\right)\right) \chi^{* E}\left(\alpha^{*}\right)\right] .
$$

This tax is less than that under full DI.

The difference in social welfare between partial insurance and no deposit insurance is given by: $\Delta\left(\alpha^{*}\right)=$ $W^{D I}\left(\alpha^{*}\right)-W^{N I}$. Our interest is in the ex post provision of partial deposit insurance. If there exists an $\alpha^{*}$ so that $\Delta\left(\alpha^{*}\right)>0$, then partial insurance, i.e. a cap on DI, will be credible.

Proposition 9 If the welfare weights are constant, then there exists $\alpha^{*}$ such that $\Delta\left(\alpha^{*}\right)>0$.

Proof. If full deposit insurance is socially desirable, as discussed above in section 4 , then $\Delta\left(\alpha^{+}\right)>0$ and the proposition holds.

If $\Delta\left(\alpha^{+}\right)<0$, then full deposit insurance will not be provided. In that case, we argue that there exists an $\alpha^{*}<\alpha+$ such that $\Delta\left(\alpha^{*}\right)>0$.

First, $\Delta\left(\alpha_{-}\right) \geq 0$. If there is no mass of households at the lower support of the endowment distribution, setting $\alpha^{*}=\alpha_{-}$is the same as no deposit insurance, so $\Delta\left(\alpha_{-}\right)=0$.

If there is a mass of households at the lower support of this distribution, then $\alpha^{*}=\alpha_{-}$provides a minimal amount of deposit insurance for all households. In this case, $\bar{T}=(1-\zeta) \chi^{* E}\left(\alpha_{-}\right)$.

Each endowment type prefers partial DI to no DI. Expected utility under partial DI is given by: $\zeta v(\bar{\alpha}+$ $\left.\chi^{* E}\left(\alpha^{0}\right)-\bar{T}\right)+(1-\zeta) v\left(\bar{\alpha}+\chi^{* E}\left(\alpha_{-}\right)-\bar{T}\right)$. Without any DI, expected utility is given by: $\zeta v\left(\bar{\alpha}+\chi^{* E}\left(\alpha^{0}\right)\right)+$ $(1-\zeta) v(\bar{\alpha})$. Expected consumption is the same with partial DI and without it. The allocation without DI is a mean-preserving spread of the allocation with partial DI. Thus all households prefer partial DI.

Consider the problem of maximizing $\Delta\left(\alpha^{*}\right)$ and thus $W^{D I}\left(\alpha^{*}\right)$. Let $\mu$ be the multiplier on (26). The two first order conditions to this maximization problem are:

$$
\begin{gathered}
\omega\left(\alpha^{*}\right) v^{\prime}\left(\bar{\alpha}+\chi^{* E}\left(\alpha^{*}\right)-\bar{T}\right)=\mu, \text { and } \\
\mu=\int_{\alpha_{-}}^{\alpha^{*}} \omega\left(\alpha^{0}\right) v^{\prime}\left(\bar{\alpha}+\chi^{* E}\left(\alpha^{0}\right)-\bar{T}\right) d F\left(\alpha^{0}\right)+ \\
\int_{\alpha^{*}}^{\alpha_{+}} \omega\left(\alpha^{0}\right)\left[(1-\zeta) v^{\prime}\left(\bar{\alpha}+\chi^{* E}\left(\alpha^{*}\right)-\bar{T}\right)+\zeta v^{\prime}\left(\bar{\alpha}+\chi^{* E}\left(\alpha^{0}\right)-\bar{T}\right)\right] d F(\alpha) .
\end{gathered}
$$


Putting these together:

$$
\begin{aligned}
& \omega\left(\alpha^{*}\right) v^{\prime}\left(\bar{\alpha}+\chi^{* E}\left(\alpha^{*}\right)-\bar{T}\right)=\int_{\alpha_{-}}^{\alpha^{*}} \omega\left(\alpha^{0}\right) v^{\prime}\left(\bar{\alpha}+\chi^{* E}\left(\alpha^{0}\right)-\bar{T}\right) d F\left(\alpha^{0}\right)+ \\
& \int_{\alpha^{*}}^{\alpha_{+}} \omega\left(\alpha^{0}\right)\left[(1-\zeta) v^{\prime}\left(\bar{\alpha}+\chi^{* E}\left(\alpha^{*}\right)-\bar{T}\right)+\zeta v^{\prime}\left(\bar{\alpha}+\chi^{* E}\left(\alpha^{0}\right)-\bar{T}\right)\right] d F(\alpha) .
\end{aligned}
$$

With constant weights, rewrite this condition as

$$
\begin{array}{r}
v^{\prime}\left(\bar{\alpha}+\chi^{* E}\left(\alpha^{*}\right)-\bar{T}\right)=\zeta \int_{\alpha_{-}}^{\alpha^{+}} v^{\prime}\left(\bar{\alpha}+\chi^{* E}\left(\alpha^{0}\right)-\bar{T}\right) d F\left(\alpha^{0}\right)+ \\
\left.(1-\zeta) \int_{\alpha_{-}}^{\alpha^{*}} v^{\prime}\left(\bar{\alpha}+\chi^{* E}\left(\alpha^{0}\right)-\bar{T}\right) d F\left(\alpha^{0}\right)+(1-\zeta) v^{\prime}\left(\bar{\alpha}+\chi^{* E}\left(\alpha^{*}\right)-\bar{T}\right)\right]\left(1-F\left(\alpha^{*}\right)\right) .
\end{array}
$$

Grouping terms, define $\Sigma\left(\alpha^{*}\right)$

$$
\begin{array}{r}
\Sigma\left(\alpha^{*}\right) \equiv\left[1-(1-\zeta)\left(1-F\left(\alpha^{*}\right)\right] v^{\prime}\left(\bar{\alpha}+\chi^{* E}\left(\alpha^{*}\right)-\bar{T}\right)-\right. \\
\zeta \int_{\alpha_{-}}^{\alpha^{+}} v^{\prime}\left(\bar{\alpha}+\chi^{* E}\left(\alpha^{0}\right)-\bar{T}\right) d F\left(\alpha^{0}\right)-(1-\zeta) \int_{\alpha_{-}}^{\alpha^{*}} v^{\prime}\left(\bar{\alpha}+\chi^{* E}\left(\alpha^{0}\right)-\bar{T}\right) d F\left(\alpha^{0}\right) .
\end{array}
$$

We argue that there exists $\alpha^{*}>\alpha_{-}$such that $\Sigma\left(\alpha^{*}\right)=0$. First, $\Sigma\left(\alpha^{*}\right)$ is decreasing in $\alpha^{*}$. The first term in (31) is decreasing in $\alpha^{*}$ as $\chi^{* E}\left(\alpha^{*}\right)-\bar{T}$ is increasing in $\alpha^{*}$. Further, the other two terms in (31) are increasing in $\bar{T}$ and hence in $\alpha^{*}$. The effects of $\alpha^{*}$ on the limit of integration in the third term cancels with the $F\left(\alpha^{*}\right)$ in the first.

Second we characterize the properties of $\Sigma(\cdot)$ at $\alpha_{-}$.

$$
\Sigma\left(\alpha_{-}\right)=v^{\prime}\left(\bar{\alpha}+\chi^{* E}\left(\alpha_{-}\right)-\bar{T}\right)-\zeta \int_{\alpha_{-}}^{\alpha^{+}} v^{\prime}\left(\bar{\alpha}+\chi^{* E}\left(\alpha^{0}\right)-\bar{T}\right) d F\left(\alpha^{0}\right) .
$$

Since $\chi^{* E}\left(\alpha_{-}\right)<\chi^{* E}\left(\alpha^{0}\right)$ for $\alpha^{0}>\alpha_{-}, \Sigma\left(\alpha_{-}\right)>0$.

Hence $\Delta\left(\alpha_{-}\right) \geq 0, \Delta^{\prime}\left(\alpha_{-}\right)>0$ and $\Delta^{\prime}(\alpha)$ is decreasing in $\alpha$. Thus there exists $\alpha^{*}>\alpha_{-}$such that $\Delta^{\prime}\left(\alpha^{*}\right)=0$. In this case, $\Delta\left(\alpha^{*}\right)>0$.

Even this policy of partial DI involves some redistribution from poor to rich. Poor households obtain full DI but less than the cap. Richer households are constrained by the cap but receive more insurance than poorer households.

Proposition 9 assumes constant weights as it balances insurance gains and redistribution losses. Nonconstant weights would impact $\alpha^{*}$. Presumably putting more weight on richer (poorer) households would increase (decrease) $\alpha^{*}$.

\subsection{Effects of Progressive Taxes}

The discussion of ex ante taxation has thus far assumed type independent taxes. This allows us to highlight the effects of the distribution of deposit claims across households which, given type independent taxes, translates into the distribution of consumption across households. 
However, when ex ante taxes are type dependent, then the tax system itself influences the distribution of consumption. All else the same, a tax system that redistributes from the poor to the rich will reduce the desirability of deposit insurance. For this discussion, we assume the welfare weights, $\omega\left(\alpha^{0}\right)$, are constant to highlight the welfare effects of the curvature in $T\left(\alpha^{0}\right)$.

Proposition 10 Compare two tax schedules, $T(\cdot)$ and $\tilde{T}(\cdot)$. If $\tilde{T}(\cdot)$ induces a MPS on disposable income relative to $T(\cdot)$ then $\Delta$ falls when we replace $T(\cdot)$ with $\tilde{T}(\cdot)$.

Proof. Since social welfare is the integral of strictly concave functions, a mean-preserving spread on disposal income, which is the same as consumption, will reduce social welfare.

To further investigate this issue, following Benabou (2002), consider a tax scheme which maps from income $\varphi$ to consumption, $c(\varphi)$ according to

$$
c(\varphi)=\varphi^{1-\tau} \bar{T}^{\tau} \cdot{ }^{15}
$$

Here $\tau$ is a tax rate and $\bar{T}^{\tau}$ is a common tax to guarantee feasibility: $\int c(\varphi) d F(\varphi)=\int \varphi d F(\varphi)$, where $F(\cdot)$ is the cdf of gross income. The constant elasticity of after-tax income (equivalently consumption here) is simply $1-\tau$. The average tax rate, $\frac{\varphi-c(\varphi)}{\varphi}=1-\bar{T}^{\tau} \varphi^{-\tau}$, is increasing in $\varphi$ if $\tau>0$.

Applying this to our model, the consumption allocation of an agent claiming to be an early consumer is $c\left(\alpha^{0}\right)=\left(\bar{\alpha}+\chi^{* E}\left(\alpha^{0}\right)\right)^{(1-\tau)} \bar{T}^{\tau}$. Here $\bar{T}^{\tau}$ guarantees that the allocation is feasible.

Proposition 11 Assume consumption allocations are given by (33). Compare two tax rates, $\tau^{L}$ and $\tau^{H}$ with $\tau^{H}>\tau^{L}>0 . \Delta$ is higher under the tax rate $\tau^{H}$ compared to $\tau^{L}$.

\section{Proof.}

From Atkinson (1970), social welfare, defined as the integral of an increasing strictly concave function of individual consumption, is higher for a consumption distribution with a Lorenz curve that lies entirely above the Lorenz curve for another distribution of consumption. The social welfare associated with the provision of deposit insurance, (10), satisfies these requirements. Hence a distribution of consumption which Lorenz-dominates another generates higher social welfare.

Kakwani (1977) provides the link between income taxes and the ordering of Lorenz curves. Note that the elasticity of consumption, $c\left(\alpha^{0}\right)$ with respect to $\bar{\alpha}+\chi^{* E}\left(\alpha^{0}\right)$ is $1-\tau$. Theorem 1 of Kakwani (1977) is interpreted in terms of the elasticity of after-tax income with respect to pre-tax income, denoted $g(x)$ in that theorem. In our application that elasticity is $1-\tau$. Hence the elasticity is lower for $\tau^{H}$ compared to $\tau^{L}$. From Theorem 1 of Kakwani (1977), this implies that the distribution of consumption under the tax rate $\tau^{H}$ Lorenz-dominates the distribution of consumption under the tax rate $\tau^{L}$. Putting these results together, social welfare is higher under the tax rate $\tau^{H}$ than under the tax rate $\tau^{L}$.

\footnotetext{
${ }^{15}$ We are grateful to Roland Benabou for discussions on this application and outlining the proof.
} 
These results highlight the implications of the tax schedule for the costs of redistribution associated with the provision of deposit insurance. Essentially, the more progressive is a tax system, the lower are these redistribution costs and thus the higher is the welfare gain (the lower is the welfare cost) from the provision of deposit insurance.

Proposition 12 Assume consumption allocations are given by (33). If $\tau$ is sufficiently high, then $\Delta$ is positive.

Proof. As $\omega\left(\alpha^{0}\right)$ is constant,

$$
\Delta=\int\left[v\left(\chi^{* E}\left(\alpha^{0}\right)+\bar{\alpha}-T\left(\alpha^{0}\right)\right)-\int\left[\zeta v\left(\chi^{* E}\left(\alpha^{0}\right)+\bar{\alpha}\right)+(1-\zeta) v(\bar{\alpha})\right] f\left(\alpha^{0}\right) d \alpha^{0} .\right.
$$

For each $\alpha^{0}$, there is a $T^{* *}\left(\alpha^{0}\right)$ such that

$$
v\left(\chi^{* E}\left(\alpha^{0}\right)+\bar{\alpha}-T^{* *}\left(\alpha^{0}\right)\right)=\zeta v\left(\chi^{* E}\left(\alpha^{0}\right)+\bar{\alpha}\right)+(1-\zeta) v(\bar{\alpha}) .
$$

Both $T^{* *}\left(\alpha^{0}\right)$ and $\chi^{* E}\left(\alpha^{0}\right)+\bar{\alpha}-T^{* *}\left(\alpha^{0}\right)$ are increasing in $\alpha^{0}$. By construction, $\Delta$ for this taxation schedule is null.

Denote by $L(\tau)$ the Lorenz curve associated with a tax scheme given by (33) and by $L^{* *}$ the Lorenz curve associated with the tax schedule $T^{* *}\left(\alpha^{0}\right)$. A Lorenz curve is always convex. The Lorenz curve associated with a given progressive taxation scheme moves up when $\tau$ increases, as well as $\Delta$, given Proposition 11 . If $\tau=1$, $L(\tau)$ is on the 45 degree line and Lorenz-dominates $L^{* *}$. For $\tau=0$, the after-tax distribution is equivalent to the pre-tax distribution and thus is Lorenz-dominated by $L^{* *}$. Hence by continuity there is a minimal value of $\tau$ (with an associated value of $\bar{T}$ ) such that the distribution of after-tax consumption associated with this ratio Lorenz-dominates the distribution of after-tax consumption associated with $T^{* *}\left(\alpha^{0}\right)$. The value of $\Delta$ associated with this minimal value of $\tau$ is weakly positive. From Proposition 11, for any value of $\tau$ which is above this minimal value, $\Delta$ is positive.

\section{Deposit Insurance and Orderly Liquidation}

As discussed in Diamond and Dybvig (1983), a key piece of government intervention is avoiding inefficient liquidation of long-term illiquid investments. As they put it, "What is crucial is that deposit insurance frees the asset liquidation policy from strict dependence on the volume of withdrawals." Thus it is important that not only deposit insurance be provided in some form but that fire sale liquidations be prevented as well. This section does so by combining the OLA and the provision of DI. Are these policies substitutes or complements? Does credibility in the provision of deposit insurance support liquidation policies that might not have otherwise been credible?

We supplement the analysis to allow both optimal liquidation and a deposit insurance scheme funded through taxation. The regulator and Treasury jointly choose the liquidation policy as well as the taxation needed to finance DI. As before, DI entails complete insurance to early households. 
The authorities jointly intervene as soon as a run is under way. Successful withdrawers in period 1 of type $\alpha^{0}$ receive $\chi^{* E}\left(\alpha^{0}\right)$ directly from the bank. Unsuccessful withdrawers receive $\chi^{* E}\left(\alpha^{0}\right)$ if they are of the early type and $\tilde{\chi}^{L}\left(\alpha^{0}\right)$ if they are late consumers. The financing of the transfers received by unsuccessful withdrawers is through taxation and (partial) liquidation of the illiquid investment. All agents are taxed according to their endowment. Using this framework, we study the optimal joint liquidation and taxation policy and whether the resulting allocation prevents a run. Finally, we return to the question of whether DI will be provided.

Given that a run has occurred and the authorities have been contacted, the optimization problem is to choose $\left(\tilde{\chi}^{L}\left(\alpha^{0}\right), Z\left(\alpha^{0}\right), Q\left(\alpha^{0}\right), T\left(\alpha^{0}\right)\right)$ to maximize:

$$
\begin{aligned}
W= & \quad \max (1-\pi)\left[\int \omega\left(\alpha^{0}\right)\left[\pi v\left(\bar{\alpha}+\chi^{* E}\left(\alpha^{0}\right)-T\left(\alpha^{0}\right)\right)+(1-\pi) v\left(\bar{\alpha}+\tilde{\chi}^{L}\left(\alpha^{0}\right)-T\left(\alpha^{0}\right)\right)\right] d F\left(\alpha^{0}\right)\right] \\
+ & \pi \int \omega\left(\alpha^{0}\right) v\left(\bar{\alpha}+\chi^{* E}\left(\alpha^{0}\right)-T\left(\alpha^{0}\right)\right) d F\left(\alpha^{0}\right) .
\end{aligned}
$$

The optimization is constrained by two resource constraints, written in per capita terms:

$$
(1-\pi) \pi \chi^{* E}\left(\alpha^{0}\right)=\epsilon Z\left(\alpha^{0}\right)+Q\left(\alpha^{0}\right)
$$

and

$$
(1-\pi)^{2} \tilde{\chi}^{L}\left(\alpha^{0}\right)=\left[\left(1-\phi\left(\alpha^{0}\right)\right) \alpha^{0}-Z\left(\alpha^{0}\right)\right] R
$$

for each $\alpha^{0}$. To guarantee incentive compatibility,

$$
\tilde{\chi}^{L}\left(\alpha^{0}\right) \geq \chi^{* E}\left(\alpha^{0}\right)
$$

for each $\alpha^{0}$. Finally, liquidation must be non-negative

$$
Z\left(\alpha^{0}\right) \geq 0
$$

for each $\alpha^{0}$.

The government budget constraint holds across the households, rather than for each $\alpha^{0}$, and is

$$
\int Q\left(\alpha^{0}\right) f\left(\alpha^{0}\right) d\left(\alpha^{0}\right)=\int T\left(\alpha^{0}\right) f\left(\alpha^{0}\right) d\left(\alpha^{0}\right) .
$$

This condition guarantees that the total amount of transfers to support the consumption of early households is financed by taxes levied on all agents, including those already served. The tax can depend on endowment type but not on the realized taste type, consistent with sequential service.

In (37), the payment to early households of $\chi^{* E}\left(\alpha^{0}\right)$ is financed either through liquidations, $Z\left(\alpha^{0}\right)$, or transfers, $Q\left(\alpha^{0}\right)$. The cost of liquidations is indicated in (38). The cost of transfers is through the collection of taxes on all households, as in (41).

The presence of DI creates a redistributive dimension to liquidation policy. Though liquidations are still, by assumption, bank specific, they now have a redistributive element across endowment types through the 
tax system. That is, liquidations at, say, a high endowment type bank can be offset by lower transfers to that bank. Instead the transfers can be used to finance the consumption of households at low endowment type banks.

We first study the optimal allocation with $F(\cdot)$ degenerate in order to understand the trade-off between liquidation and taxation without redistribution across income groups. Building on this, we then study the problem with heterogenous households.

Proposition 13 If $F(\cdot)$ is degenerate, then there is exists a critical $\left(\frac{R}{\epsilon}\right)^{c}$ such that the solution to (36) sets $Z>0$ if $\frac{R}{\epsilon}<\left(\frac{R}{\epsilon}\right)^{c}$ and $Z=0$ otherwise. Runs are prevented.

Proof. When $F(\cdot)$ is degenerate, the tax on each household is $\bar{T}=\chi^{* E}(1-\pi) \pi-\epsilon Z$ from (37). Inserting this into the consumption levels of early and late consumers there is a single first-order condition associated with the choice of Z:

$$
\frac{\lambda^{z}}{\epsilon}=(1-\pi)^{2} v^{\prime}\left(c^{L}\right)\left(\frac{R}{\epsilon(1-\pi)^{2}}-1\right)-(2-\pi) \pi v^{\prime}\left(c^{* E}\right)
$$

where $\lambda^{z}$ is the multiplier associated with $(40), c^{* E}=\bar{\alpha}+\chi^{* E}\left(\alpha^{0}\right)-\chi^{* E}(1-\pi) \pi+\epsilon Z$ and $\tilde{c}^{L}=\bar{\alpha}+\tilde{\chi}^{L}\left(\alpha^{0}\right)-$ $\chi^{* E}(1-\pi) \pi+\epsilon Z$.

Define $\left(\frac{R}{\epsilon}\right)^{c} \equiv(1-\pi)^{2}+(2-\pi) \frac{v^{\prime}\left(c^{* E}\right)}{v^{\prime}\left(\tilde{c}^{L}\right)}$ with $Z=0 .{ }^{16}$ Note that $c^{* E}$ and $\tilde{c}^{L}$ are independent of $(R, \epsilon)$ when $Z=0$.

If $\frac{R}{\epsilon}>\left(\frac{R}{\epsilon}\right)^{c}, \lambda^{z}>0$ for (42) to hold. In this case, $\tilde{c}^{L}>c^{* L}>c^{* E}$. Hence, the allocation is both incentive compatible and runs proof. If $\frac{R}{\epsilon} \leq\left(\frac{R}{\epsilon}\right)^{c}, \lambda^{z}=0$ for (42) to hold and there are liquidations. In this case, (42) becomes

$$
v^{\prime}\left(c^{L}\right)\left(\frac{R}{\epsilon}-(1-\pi)^{2}\right)=(2-\pi) \pi v^{\prime}\left(c^{* E}\right) .
$$

As $(2-\pi) \pi=1-(1-\pi)^{2}, c^{L}>c^{* E}$ for $(42)$ to hold. Thus the allocation is both incentive compatible and there is no run.

The degenerate case indicates that liquidation is sub-optimal when its cost, $\frac{R}{\epsilon}$, is too large. Instead, redistribution arises through the tax system. However, if $\frac{R}{\epsilon}$ is small enough, liquidation is used for redistribution since it is a more direct way to transfer resources from the late households to the early ones not served during the run.

As we shall see, this is not necessarily the case when there are heterogeneous households. The system of lump-sum taxes is regressive, redistributing from poor to rich households. Consequently, liquidations may coexist along with the use of the tax system to finance DI.

To see this interaction, assume that taxes are lump-sum and independent of the endowment type: $T\left(\alpha^{0}\right)=$ $\bar{T}$ for all $\alpha^{0}$. The following proposition characterizes the optimal liquidation policy:

\footnotetext{
${ }^{16}$ Here we focus on $\left(\frac{R}{\epsilon}\right)^{c}$ instead of the critical $\alpha$ in Proposition 3.
} 
Proposition 14 If taxes are independent of $\alpha^{0}, \omega\left(\alpha^{0}\right)$ is constant and $\epsilon>0$, the solution to (36) entails no liquidations for low values of $\alpha^{0}$ and positive liquidation for sufficiently high values of $\alpha^{0}$. Runs are prevented.

Proof. When $F(\cdot)$ is not degenerate, the lump sum tax on each household is

$$
\bar{T}=\int\left[(1-\pi) \pi \chi^{E}\left(\alpha^{0}\right)-\epsilon Z\left(\alpha^{0}\right)\right] d F\left(\alpha^{0}\right) .
$$

Substituting this into the consumption levels of early and late consumers, the first-order condition associated with the choice of $Z\left(\alpha^{0}\right)$ is:

$$
\left.\int\left[(2-\pi) \pi v^{\prime}\left(c^{* E}(x)\right)\right)+(1-\pi)^{2} v^{\prime}\left(\tilde{c}^{L}(x)\right)\right] d F(x)-v^{\prime}\left(\tilde{c}^{L}\left(\alpha^{0}\right)\right) \frac{R}{\epsilon}+\lambda^{I C}\left(\alpha^{0}\right)+\frac{\lambda^{z}\left(\alpha^{0}\right)}{\epsilon}=0
$$

where $\lambda^{z}\left(\alpha^{0}\right)$ is the multiplier associated with (40) and $\lambda^{I C}\left(\alpha^{0}\right)$ is the multiplier associated with (39) for type $\alpha^{0}, c^{* E}(x)=\bar{\alpha}+\chi^{* E}(x)-\bar{T}$ and $\tilde{c}^{L}(x)=\bar{\alpha}+\tilde{\chi}^{L}(x)-\bar{T}$ where $x$ indicates an arbitrary level of endowment. The first term is common to all of the first-order conditions with respect to $Z(\cdot)$. The other terms are type $\alpha^{0}$ specific. The solution is continuous in $\alpha^{0}$ from the maximum theorem.

We initially study the solution when the incentive compatibility constraint is not binding. Later we return to this initial stipulation.

If $\lambda^{Z}\left(\hat{\alpha}^{0}\right)>0$, then for any $\alpha^{0}<\hat{\alpha}^{0}, Z\left(\alpha^{0}\right)=0$ as well in order for (46) to hold. To see this, suppose $\alpha^{0}<\hat{\alpha}^{0}$ but $Z\left(\alpha^{0}\right)>0$. From (38), $Z\left(\alpha^{0}\right)>0$ implies that $\tilde{\chi}^{L}\left(\alpha^{0}\right)<\frac{\chi^{* L}\left(\alpha^{0}\right)}{1-\pi}$ while $Z\left(\alpha^{0}\right)=0$ implies $\tilde{\chi}^{L}\left(\hat{\alpha}^{0}\right)=\frac{\chi^{* L}\left(\hat{\alpha}^{0}\right)}{1-\pi}$.

From Proposition 1, $\hat{\alpha}^{0}>\alpha^{0}$ implies $\chi^{* L}\left(\hat{\alpha}^{0}\right)>\chi^{* L}\left(\alpha^{0}\right)$. Using this, $\tilde{\chi}^{L}\left(\hat{\alpha}^{0}\right)>\tilde{\chi}^{L}\left(\alpha^{0}\right)$. For (46) to hold, $\lambda^{Z}\left(\hat{\alpha}^{0}\right)>0$ and $\lambda^{Z}\left(\alpha^{0}\right)=0$ implies $\tilde{\chi}^{L}\left(\alpha^{0}\right)>\tilde{\chi}^{L}\left(\hat{\alpha}^{0}\right)$. This is a contradiction.

By this same argument, if $Z\left(\hat{\alpha}^{0}\right)>0$ and $\lambda^{Z}\left(\hat{\alpha}^{0}\right)=0$, then for any $\alpha^{0}>\hat{\alpha}^{0}, Z\left(\alpha^{0}\right)>0$ as well. Thus there is a critical value of $\alpha^{0}$ such that there are liquidations only for endowment types above this level.

By continuity, there exists $\tilde{\alpha}^{0}$ such that $Z\left(\tilde{\alpha}^{0}\right)=0$ and $\lambda^{Z}\left(\tilde{\alpha}^{0}\right)=0$. Here there are no liquidations and the constraint is not binding. The first-order condition with respect to liquidation for this type would be

$$
\left.\int\left[(2-\pi) \pi v^{\prime}\left(c^{* E}(x)\right)\right)+(1-\pi)^{2} v^{\prime}\left(\tilde{c}^{L}(x)\right)\right] d F(x)=v^{\prime}\left(\tilde{c}^{L}\left(\tilde{\alpha}^{0}\right)\right) \frac{R}{\epsilon} .
$$

From the arguments above, for $\alpha^{0}<\tilde{\alpha}^{0}, Z\left(\alpha^{0}\right)=0$ and $\tilde{\chi}^{L}\left(\alpha^{0}\right)$ will be increasing in $\alpha^{0}$. From $\alpha^{0}>\tilde{\alpha}^{0}$, $Z\left(\alpha^{0}\right)>0$. If the distribution of $\alpha^{0}$ is sufficiently dispersed, $\tilde{\alpha}$ will be interior.

To see that the allocations are incentive compatible, for $\alpha^{0}<\tilde{\alpha}$ there are no liquidations and $\tilde{\chi}^{L}\left(\alpha^{0}\right)>$ $\chi^{* L}\left(\alpha^{0}\right)>\chi^{* E}\left(\alpha^{0}\right)$ so late households have higher consumption than early ones. When there is liquidation, (45) holds with $\lambda^{z}\left(\alpha^{0}\right)=0$. If the incentive compatibility constraint is not binding, then $\tilde{\chi}^{L}\left(\alpha^{0}\right)$ will be independent of $\alpha^{0}$.

As noted above, we stipulated that the incentive compatibility condition was not binding. But it can be that in the solution without this constraint, the consumption levels of late high $\alpha^{0}$ households will fall 
below $\chi^{* E}\left(\alpha^{0}\right)$. In this event, the solution to (45) must be modified to allow $\tilde{\chi}^{L}\left(\alpha^{0}\right) \geq \chi^{* E}\left(\alpha^{0}\right)$ to bind for sufficiently large $\alpha^{0}$.

In (45), this implies that $\lambda^{I C}\left(\alpha^{0}\right)>0$. Consequently, the liquidations from the high $\alpha^{0}$ will be modified so that the outcome is incentive compatible. Note that there must still be liquidations for the high $\alpha^{0}$ households. Else, they will receive $\tilde{\chi}^{L}\left(\alpha^{0}\right)>\chi^{* L}\left(\alpha^{0}\right)>\chi^{* E}\left(\alpha^{0}\right)$ and the incentive constraint will not be binding.

In either case, the contract satisfies the incentive compatibility condition. Since all early consumers obtain the same level of consumption whether they were served initially or not, the incentive compatibility condition, $\tilde{\chi}^{L}\left(\alpha^{0}\right)>\chi^{* E}\left(\alpha^{0}\right)$, implies the contract is runs-proof.

Figure 4 illustrates the solution. There are two critical levels of $\alpha^{0}$. For $\alpha^{0} \leq \tilde{\alpha}$, there are no liquidations and $\tilde{\chi}^{L}\left(\alpha^{0}\right)$ is larger than $\chi^{* L}\left(\alpha^{0}\right)$ and hence larger than $\chi^{* L}\left(\alpha^{0}\right)$. For $\alpha^{0}>\tilde{\alpha}$ there are optimal liquidations. Over this region, $\tilde{\chi}^{L}\left(\alpha^{0}\right)$ is independent of $\alpha^{0}$ as liquidations increase in $\alpha^{0}$. For $\alpha^{0}>\alpha^{I C}$, the incentive constraint binds so that $\tilde{\chi}^{L}\left(\alpha^{0}\right)=\chi^{* E}\left(\alpha^{0}\right)$.

Figure 4: Optimal Liquidation with Deposit Insurance

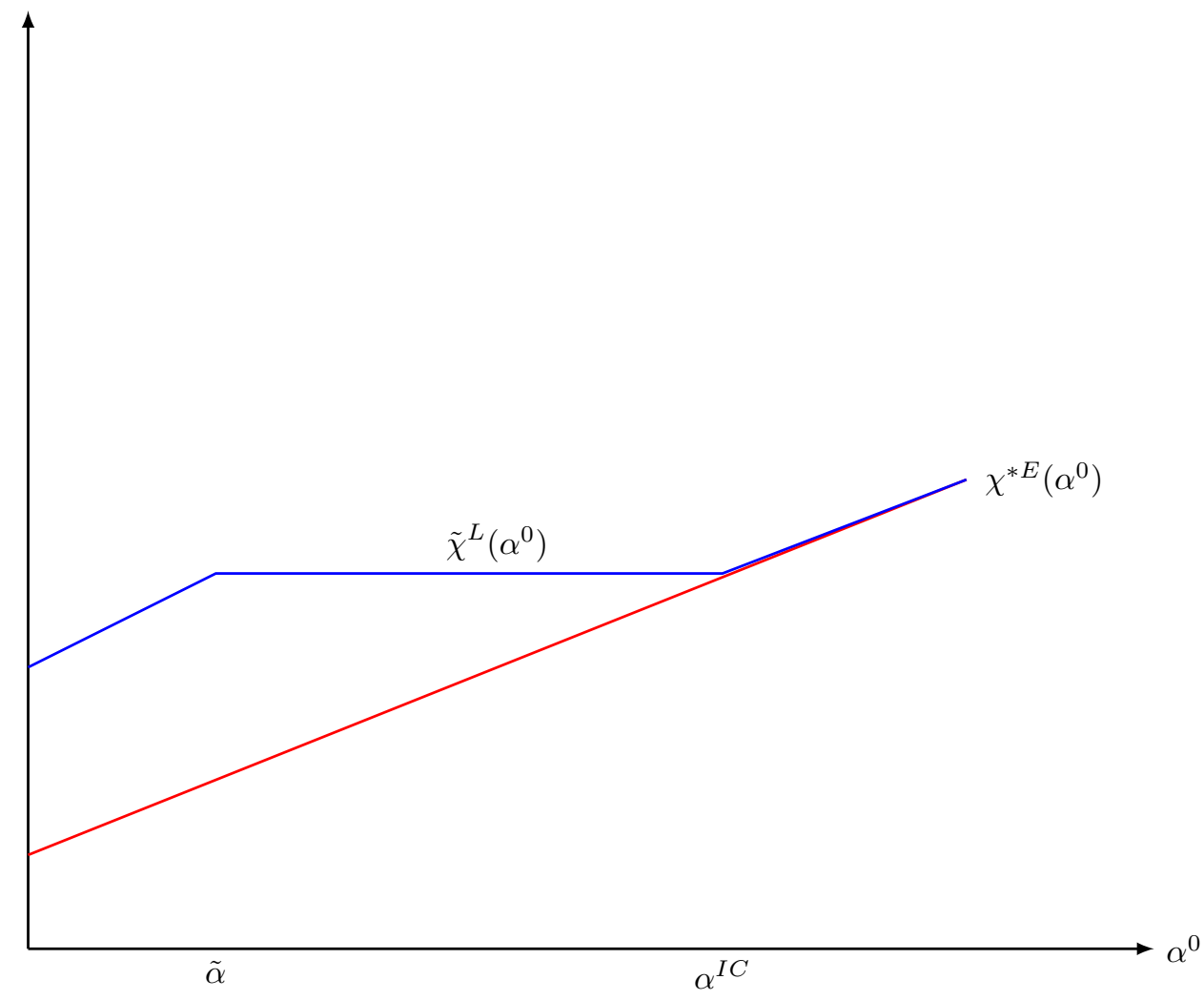

This result shows the power of an integrated regulator and Treasury. The liquidation policy is optimal: relatively poor late households' illiquid investment is left intact to fund their late consumption. For relatively rich households, there is some liquidation of the illiquid investment. This liquidated investment along with 
the revenues from the lump-sum tax are used to support the consumption of early households.

The proposition assumes a constant welfare weight. If $\omega\left(\alpha^{0}\right)$ is not constant, then of course the relative gains and costs of redistribution will enter in the analysis. These effects are apparent from earlier results, such as Proposition 6.

The main finding is that even with a lump-sum tax, the joint intervention of providing deposit insurance along with an optimal liquidation policy is sufficient to eliminate bank runs. And these policies are all implemented without commitment.

With these results, we return to one of the central questions of the paper: will DI be provided? Compared to the difference in social welfare with and without deposit insurance, recall (17), the gains to deposit insurance must be larger since the liquidation policy is optimal. As indicated in Proposition 15, the optimal policy is to liquidate the investment of high $\alpha^{0}$ types while the liquidation underlying (17) was total. Hence the gains to deposit insurance must be larger when there is optimal liquidation compared to a setting with total liquidation.

Still, this does not imply that deposit insurance will be provided. As before, the redistribution costs may outweigh insurance gains.

These results assume that taxes are lump-sum. This was intended to highlight the resolution of the resulting tension between redistribution through DI and efficient liquidation. Both costly liquidation and taxation are used to finance DI and redistribute across heterogeneous agents. Liquidation arises because the tax system is not sufficiently flexible to offset the undesirable aspects of DI.

From Proposition 5, if taxes are set optimally ex post and are dependent on $\alpha^{0}$, then deposit insurance is provided and runs are prevented. That result will clearly carry over to the case of optimal liquidation along with deposit insurance since the allocation from Proposition 5 is nested in the version of (36) allowing type dependent taxes. This leads us to a final result on the provision of DI along with optimal liquidation.

Proposition 15 If taxes depend on the endowment type, the solution to (36) entails no liquidations, no runs and the intervention is welfare improving.

Proof. The result that the intervention is welfare improving comes from the fact that in the solution to (36) total liquidation is feasible. Thus the welfare from the solution to (36) cannot be less than the outcome with total liquidation, (15), that, as shown in Proposition 5, dominates the bank runs outcome. Thus the provision of DI along with optimal liquidation is welfare improving. Since the solution to (36) is incentive compatible, it must be runs-proof.

The first-order conditions for (36) are

$$
\begin{gathered}
\epsilon \lambda^{E}\left(\alpha^{0}\right)-R \lambda^{L}\left(\alpha^{0}\right)+\lambda^{Z}\left(\alpha^{0}\right)=0, \\
\lambda^{E}\left(\alpha^{0}\right)=\mu,
\end{gathered}
$$




$$
(1-\pi)^{2}\left[v^{\prime}\left(c^{L}\left(\alpha^{0}\right)\right)-\lambda^{L}\left(\alpha^{0}\right)\right]+\lambda^{I C}\left(\alpha^{0}\right)=0,
$$

and

$$
\pi(2-\pi) v^{\prime}\left(c^{E}\left(\alpha^{0}\right)\right)+(1-\pi)^{2} v^{\prime}\left(c^{L}\left(\alpha^{0}\right)\right)=\mu .
$$

From the incentive compatibility constraint, for (50) to hold,

$$
v^{\prime}\left(c^{E}\left(\alpha^{0}\right)\right) \geq \mu \geq v^{\prime}\left(c^{L}\left(\alpha^{0}\right)\right) .
$$

Using this in (49) implies

$$
(1-\pi)^{2}\left[\mu-\lambda^{L}\left(\alpha^{0}\right)\right]+\lambda^{I C}\left(\alpha^{0}\right) \geq 0 .
$$

Use (47) and (48) to solve for $\mu$ and substitute into (52) to yield:

$$
(1-\pi)^{2}\left[\left(\frac{R}{\varepsilon}-1\right) \lambda^{L}\left(\alpha^{0}\right)-\frac{\lambda^{z}\left(\alpha^{0}\right)}{\varepsilon}\right]+\lambda^{I C}\left(\alpha^{0}\right) \geq 0 .
$$

Since $\frac{R}{\varepsilon}-1>0, \lambda^{z}\left(\alpha^{0}\right)>0$ in order for (53) to hold. Thus there are no liquidations.

The flexible tax system facilitates redistribute across households by their wealth types. The liquidation scheme which redistributes across households by their tastes, early or late, within a wealth type is dominated by the tax system. Thus costly liquidation is avoided.

In fact, the ex post provision of DI is sufficient to made the suspension of withdrawals credible. The commitment problem on liquidation, highlighted by Ennis and Keister (2009), is not present when DI is credibly provided. That is, a policy to suspend withdrawals once $\pi$ households have been served is credible once it is backed by a DI system. Runs are avoided.

\section{Conclusion}

This paper studies liquidation policy and the provision of deposit insurance in the absence of commitment. The goal is to characterize these interventions and to see if they are sufficient to prevent bank runs.

Intervention through the control of liquidation policy is appropriate for considering the regulation of financial intermediaries not covered by a deposit insurance scheme. For these institutions, if liquidation is very costly, then the optimal amount of liquidation is limited. This protects illiquid assets and helps to avoid runs. In other circumstances, the illiquid assets of wealthy investors will be partially liquidated to transfer resources to households with liquidity needs. These transfers can be large enough ex post that this intervention may not prevent a run.

We interpret deposit insurance broadly to encompass a variety of forms of ex post bailout of financial intermediaries. While steps taken recently to support the financial system in a number of countries may have 
been warranted, these ex post interventions have a consequence: agents will now realize that governments will make ex post decisions on deposit insurance.

If so, it is natural to investigate the conditions under which deposit insurance will be supplied ex post. Initially we do so assuming full liquidation prior to the provision of DI. In our environment with differences in deposit levels, a trade-off emerges between risk sharing and the redistribution created by the funding of the transfers inherent in a deposit insurance system. In some cases, these redistribution costs may be large enough to offset insurance gains. These costs are reflected in the ongoing discussion of bailouts in the U.S. and other countries insofar as those policies entail a regressive redistribution.

From our analysis, the tax system used to finance payments to depositors plays a crucial role in determining whether deposit insurance will be provided. If the tax system is set ex post along with deposit insurance, then the government can optimally choose the net transfer and avoid the conflict between insurance and redistribution. But if the deposit insurance must be financed by an ex ante tax system that allows for redistributions from the poor to the rich through the provision of deposit insurance, then the credibility of deposit insurance is weakened. This was illustrated through our discussion of lump-sum taxes.

When optimal liquidation and the provision of deposit insurance are put together, the optimal arrangement may involve some liquidation of illiquid assets held by high wealth investors. If taxes are optimally set ex post and are dependent on the endowment type, then no liquidations arise. In either case, the resulting allocation is runs-proof.

Throughout the paper, we assumed a simple bank contract that ignored the prospect of runs. Further, the contract did not link the return to an agent to its "place in line". Nor did we allow the suspension of withdrawals unilaterally by a bank. Instead, suspension was handled through the regulator. These restrictions on the optimal contract support the full information solution. As long as the combination of optimal regulation and deposit insurance are provided ex post, this simple contract is privately optimal and runs-proof as well.

\section{References}

Atkinson, A. (1970): "On the measurement of inequality," Journal of economic theory, 2(3), 244-263.

Benabou, R. (2002): "Tax and education policy in a heterogeneous-agent economy: what levels of redistribution maximize growth and efficiency?," Econometrica, 70(2), 481-517.

Chari, V., and P. Kehoe (1990): "Sustainable plans," Journal of Political Economy, pp. 783-802.

Cooper, R., And H. Kempf (2011): "Deposit Insurance Without Commitment: Wall St. Versus Main St," NBER Working Paper \# 16752.

Cooper, R., H. Kempf, and D. Peled (2008): "Is it is or it is ain't my obligation? Regional Debt in a Fiscal Federation," International Economic Review, 49, 1469-1504. 
Cooper, R., And T. Ross (1998): "Bank runs: liquidity costs and investment distortions," Journal of Monetary Economics, 41(1), 27-38.

DemirgüÇ-Kunt, A., And T. SobACi (2001): "A new development database. Deposit insurance around the world," The World Bank Economic Review, 15(3), 481-490.

Diamond, D., And P. Dybvig (1983): "Bank Runs, Deposit Insurance and Liquidity," Journal of Political Economy, 91, 401-19.

Ennis, H., And T. KeISTER (2009): "Bank runs and institutions: the perils of intervention," The American Economic Review, 99(4), 1588-1607.

Green, E., and P. Lin (2000): "Diamond and Dybvig's classic theory of financial intermediation: what's missing?," Federal Reserve Bank of Minneapolis Quarterly Review, 24(1), 3-13.

KAKWANi, N. (1977): "Applications of Lorenz curves in economic analysis," Econometrica: Journal of the Econometric Society, pp. 719-727.

Keister, T. (2010): "Bailouts and Financial Fragility," Federal Reserve Bank of New York, Staff Report no. 473 .

Peck, J., And K. Shell (2003): "Equilibrium bank runs," Journal of Political Economy, 111(1), 103-123.

Wallace, N. (1988): "Another attempt to explain an illiquid banking system: The Diamond and Dybvig model with sequential service taken seriously," Federal Reserve Bank of Minneapolis Quarterly Review, $12(4), 3-16$. 